\title{
Rac GTPase Plays an Essential Role in Exocytosis by Controlling the Fusion Competence of Release Sites
}

\author{
Yann Humeau, ${ }^{1}$ Michel R. Popoff, ${ }^{2}$ Hiroshi Kojima, ${ }^{1}$ Frédéric Doussau, ${ }^{1}$ and Bernard Poulain ${ }^{1}$ \\ ${ }^{1}$ Neurotransmission et Sécrétion Neuroendocrine, UPR2356 du Centre National de la Recherche Scientifique, \\ IFR-37 des Neurosciences, F-67084 Strasbourg Cedex, France, and ${ }^{2}$ Toxines Microbiennes, Institut Pasteur, \\ F-75724 Paris Cedex 15, France
}

The role of small GTPases of the Rho family in synaptic functions has been addressed by analyzing the effects of lethal toxin (LT) from Clostridium sordellii strain IP82 (LT82) on neurotransmitter release at evoked identified synapses in the buccal ganglion of Aplysia. LT82 is a large monoglucosyltranferase that uses UDP-glucose as cofactor and glucosylates Rac (a small GTPase related to Rho), and Ras, Ral, and Rap (three GTPases of the Ras family). Intraneuronal application of LT (50 nM) rapidly inhibits evoked acetylcholine (ACh) release as monitored electrophysiologically. Injection of the catalytic domain of the toxin similarly blocked ACh release, but not when key amino acids needed for glucosylation were mutated. Intraneuronal application of competitive nucleotide sugars that differentially prevent glucosylation of Rac- and Ras-related GTPases, and the use of a toxin variant that affects a different spectrum of small GTPases, established that glucosylation of Rac is responsible for the reduction in ACh release. To determine the quantal release parameters affected by Rac glucosylation, we developed a nonstationary analysis of the fluctuations in postsynaptic response amplitudes that was performed before and after the toxin had acted or during toxin action. The results indicate that neither the quantal size nor the average probability for release were affected by lethal toxin action. ACh release blockage by LT82 was only caused by a reduction in the number of functional release sites. This reveals that after docking of synaptic vesicles, vesicular Rac stimulates a membrane effector (or effectors) essential for the fusion competence of the exocytotic sites.

Key words: Aplysia; synapse; exocytosis; quantal parameters; synaptic vesicle fusion; Rho-GTPases; clostridial toxins; fluctuation analysis
Rho proteins (Rho, Rac, Cdc42) are widely expressed monomeric GTPases. They cycle between a soluble, GDP-bound inactive state and a membrane-associated GTP-bound state that stimulates downstream effectors. The effectors include protein kinase $\mathrm{N}$, Rho-kinase, the myosin-binding subunit of myosin phosphatase, several phosphatidylinositol protein kinases (PI3-kinase, PI4-kinase, PI5-kinase), and phospholipase C and phospholipase $\mathrm{D}$ (PLD). Despite the ubiquitous distribution of cytosolic RhoGTPases, their translocation to specific membrane domains allows them to intervene in distinct biological functions such as regulation of actin cytoskeletal dynamics, cell cycle progression, gene transcription, and membrane transport (Hall, 1998; Bishop and Hall, 2000; Ridley, 2001). Recently, Rho, Rac, and Cdc42 have been implicated in the regulation of neuronal morphogenesis (axonal guidance, maintenance of dendritic spines and branching) (Luo, 2000; Nakayama et al., 2000; Dickson, 2001; Liu

\footnotetext{
Received May 28, 2002; revised June 24, 2002; accepted June 26, 2002.

This work was supported by grants from the Association Française contre les Myopathies, DSP contract 99-34-038 to B.P., and Programme de Recherche Fondamentale en Microbiologie et sur les Maladies Infectieuses et Parasitaires 2000 (to B.P. and M.R.P.). We thank Drs. Fabio Benfenati (Università di Genova, Italy) and Nancy Grant (Unité Propre de Recherche 2356 du Centre National de la Recherche Scientifique, Strasbourg, France) for critical reading of this manuscript, and Tamou Thahouly for excellent technical assistance.

Correspondence should be addressed to Bernard Poulain, Neurotransmission et Sécrétion Neuroendocrine, Unité Propre de Recherche 2356 du Centre National de la Recherche Scientifique, 5, rue Blaise Pascal, F-67084 Strasbourg Cedex, France. E-mail: poulain@neurochem.u-strasbg.fr.

Y. Humeau's present address: PharmaZentrum, Klingelbergstrasse 50, CH-4056 Basel, Swizerland.

H. Kojima's present address: Department of Molecular Biology, Princeton University, Princeton, NJ 08544.

Copyright (C) 2002 Society for Neuroscience $\quad 0270-6474 / 02 / 227968-14 \$ 15.00 / 0$
}

and Strittmatter, 2001; Redmond and Ghosh, 2001), control of neurotransmitter-receptor density (Meyer et al., 2000), and induction of neuronal apoptosis (Linseman et al., 2001; Mota et al., 2001). Our previous findings that RhoA, RhoB, Rac1, and Cdc42 are present in nerve terminals and that Rac1 is associated with synaptic vesicles (SVs) (Doussau et al., 2000) have suggested that these GTPases may also play a role in neurotransmitter release.

The cellular function of endogenous Rho and Ras proteins can be acutely manipulated by using bacterial protein toxins that modify and inactivate them in a highly specific manner (Busch and Aktories, 2000; Just and Boquet, 2000). Clostridium sordellii lethal toxin (LT) glucosylates a conserved threonine in the effector domain of Rac (which is related to Rho), and Ras, Rap, and Ral, (which are members of the Ras family). LT variants have been reported to also affect $\mathrm{Cdc} 42$. When glucosylated, the RhoGTPases can associate with target membranes but cannot activate their effectors, thereby silencing the downstream pathways (Just et al., 1996; Popoff et al., 1996; Busch and Aktories, 2000; Just and Boquet, 2000).

We have found previously that intraneuronal injection of LT or toxins that glycosylate or ADP-ribosylate Rho-related GTPases blocks acetylcholine (ACh) release at Aplysia synapses (Doussau et al., 2000). This indicates that members of the Rho family play a role in neurotransmitter exocytosis and extends to neurons the idea that Rho-related proteins control secretion mechanisms (Prepens et al., 1996; Kowluru et al., 1997; Brown et al., 1998; Gasman et al., 1998, 1999; Djouder et al., 2000; Hong-Geller and Cerione, 2000; Guo et al., 2001).

To identify the key GTPase(s) whose inactivation is responsible for the LT-blocking action on ACh release, we have investi- 
gated the causal relationship between the glycosylating activity of two LT variants that each affect a distinct set of GTPases and inhibition of neurotransmitter release at identified Aplysia synapses. We found that ACh release blockage is caused by glucosylation of Rac GTPase. To determine the release step(s) altered after LT application, we analyzed the fluctuations in postsynaptic response amplitudes before and during LT-induced blocking action. Our results show a decrease in the number of active release sites, but quantal size and release probability are unaltered. This reveals that the Rac-mediated pathway is implicated in the activation of release sites.

\section{MATERIALS AND METHODS}

\section{Preparation of toxins and determination of their glucosylating activity}

The toxins were purified from C. sordellii IP82 (LT82) and VPI9048 (LT9048) strains as described previously (Popoff, 1987). The DNA coding for the $546 \mathrm{~N}$-terminal amino acids, which contain the enzymatic site (Hofmann et al., 1998), was amplified by PCR from C. sordellii IP82 strain. Primers were taken from the LT gene sequence (Green et al., 1995), and XSalI and XhoI sites were added at the $5^{\prime}$ and $3^{\prime}$ ends of the coding sequence, respectively. The resulting PCR DNA fragment was cloned into the corresponding sites of pET28b (Novagen). The plasmid was transformed into the Escherichia coli BL21 strain, and production of the 6 His-tag fusion protein was induced with isopropyl-1-thio- $\beta$-Dgalactopyranoside. Purification was performed with a cobalt column (Novagen) according to the recommendations of the manufacturer. An inactive mutant of the LT82 N-terminal part (Ala-286-Asp, Ala-288Asp) was prepared as described previously (Busch et al., 1998), and the protein was produced and purified as mentioned above.

Recombinant small GTPases were produced in $E$. coli, purified with glutathione-Sepharose 4B (Amersham Biosciences), and prepared by thrombin digestion according to the recommendations of the manufacturer. Rho, Rac1, and Cdc42 clones were a generous gift from Dr. Alan Hall (London, UK). H-Ras, Rap1a, and RalC clones were kindly donated by Dr. Robert Cool (Max Plank Institute, Dortmund, Germany).

In vitro glucosylation of small GTPases was performed in $50 \mathrm{~mm}$ triethanolamine, $\mathrm{pH} 7.5$, containing $2 \mu \mathrm{l}$ of UDP- ${ }^{14} \mathrm{C}$-glucose (DuPont $\mathrm{NEN}$; $286.2 \mathrm{mCi} / \mathrm{mmol}$; final concentration $7 \mu \mathrm{M}), 2 \mathrm{mM} \mathrm{MgCl}_{2}, 1 \mathrm{~mm}$ DTT, $0.3 \mathrm{~mm}$ GDP, $1 \mu \mathrm{g}$ of recombinant GTPase, and $5 \mu \mathrm{g} / \mathrm{ml} \mathrm{LT} 82$, LT82 recombinant fragment, or LT9048. The reaction was performed for $1 \mathrm{hr}$ at $37^{\circ} \mathrm{C}$ and stopped by adding $10 \mu \mathrm{l}$ of sample buffer (three times) followed by boiling for $3 \mathrm{~min}$. Then samples were electrophoresed on a $15 \%$ SDS-PAGE and autoradiographed. When necessary, UDPmannose, ADP-glucose, and TDP-glucose (Sigma) were used to prevent glucosylation.

\section{Detection and glucosylation of small GTPases in Aplysia}

Aplysia californica (70-120 gm body weight; Marinus Inc., Long Beach, CA) were anesthetized by injection of $50-75 \mathrm{ml}$ of solution containing $400 \mathrm{mM} \mathrm{MgCl}_{2}$, and the nervous system was removed. Freshly dissected nerve ganglia (buccal, cerebral, pleural, pedal, and abominal) were homogenized in Tris buffer containing $10 \mathrm{~mm}$ Tris, $\mathrm{pH}$ 7.5, $2 \mathrm{mM} \mathrm{MgCl}_{2}$, $1 \mathrm{~mm}$ DTT, $10 \mu \mathrm{g} / \mathrm{ml}$ leupeptin, $1 \mu \mathrm{M}$ pepstatin, and $0.1 \mathrm{~mm}$ PMSF. Complete lysis was achieved by three cycles of freeze thawing.

Detection of Aplysia GTPases. Total proteins were extracted in Tris buffer containing $1 \%$ Triton $\mathrm{X}-100$ for $20 \mathrm{~min}$ at room temperature. For Western blotting, samples containing $20 \mu \mathrm{g}$ Aplysia proteins were subjected to SDS-PAGE on $15 \%$ gels, transferred to nitrocellulose, and incubated with a 1:50 dilution of antibodies against small GTPases in PBS-milk at room temperature for $16 \mathrm{hr}$. Polyclonal rabbit antibodies against Rho, Ras, Rap, and Ral were from Santa Cruz Biotechnology; anti-Rac1 was from Upstate Biotechnology. Polyclonal rabbit antibodies directed against $\mathrm{Cdc} 42$ were kindly provided by Dr. Philippe Chavrier (Institut Curie, Paris, France). Immunoblots were processed with peroxidase conjugate and chemiluminescence kit (ECL, Amersham) and analyzed by autoradiography.

Glucosylation of Aplysia GTPases. Lysates were centrifuged (15,000 rpm for $15 \mathrm{~min}$ ) to separate a pellet containing membrane fractions [denoted as insoluble (I) fraction] and a fraction containing cytosolic and crude vesicle fractions [denoted as soluble (S) fraction]. The pellet was washed four times with distilled water and extracted with the buffer described above, but containing $1 \%$ Triton $\mathrm{X}-100$, for 20 min at room temperature. Total proteins were assayed using a manufactured protein assay (Bio-Rad Life Science, Marne la Coquette, France). Glucosylation was performed on samples (100 $\mu \mathrm{g}$ protein) of the soluble and insoluble fractions as described above.

\section{Acetylcholine release and electrical recordings at Aplysia synapses}

Electrophysiological experiments were performed at identified, chloridedependent, inhibitory cholinergic synapses in dissected buccal ganglia of Aplysia as described previously (Poulain et al., 1986, 1988; Schiavo et al., 1992; Doussau et al., 1998, 2000; Humeau et al., 2001a,b). Two presynaptic cholinergic interneurons termed B4 and B5 (Gardner, 1971) and one postsynaptic neuron (either B3 or B6) were impaled with two glass microelectrodes $(3 \mathrm{M} \mathrm{KCl}, \mathrm{Ag} / \mathrm{AgCl} 2,2-10 \mathrm{M} \Omega$ ). To initiate action potentials and evoke $\mathrm{ACh}$ release, the presynaptic neurons were depolarized by a square pulse of $50 \mathrm{msec}$ duration and appropriate intensity. To avoid overlap of the postsynaptic responses originating from the two B4 and B5 presynaptic neurons, the stimulus protocols were alternated, and each presynaptic neuron was stimulated every $40 \mathrm{sec}(0.025 \mathrm{~Hz})$.

Evoked ACh release was monitored by measuring the amplitude of the evoked IPSCs using the conventional two-electrodes voltage-clamp technique (AxoClamp2B, Axon Instruments). The postsynaptic currents are purely chloride dependent (Gardner and Stevens, 1980; Simonneau et al., 1980; Kehoe and McIntosh, 1998). Moreover, to measure accurately the amplitude of the postsynaptic response, the holding potential $V_{\mathrm{h}}$ was maintained at $30 \mathrm{mV}$ above the reversal potential of postsynaptic responses, $V_{\text {rev }} . V_{\text {rev }}$ was determined every $5 \mathrm{~min}$. The recordings were digitized at $40 \mathrm{kHz}$ and filtered at a cutoff frequency of $250 \mathrm{~Hz}$ using an eight-pole low-pass Bessel type filter (902LPS, Frequency Device).

To express the amplitude of the IPSC as a value proportional to the amount of released ACh but independent of the driving force for $\mathrm{Cl}^{-}$, the IPSC amplitude was converted as an apparent membrane conductance $(G)$ by taking into account the reversal potential $V_{\text {rev }}$ (at these synapses, $\left.V_{\text {rev }}=E_{\mathrm{Cl}-}\right)$ of the evoked response according to the equation $G=I /\left(V_{\mathrm{h}}-V_{\text {rev }}\right)$. However, although the postsynaptic response amplitude has the dimension of a membrane conductance, we refer to it in this paper as the IPSC amplitude, $I$ (nanosiemens).

\section{Extracellular media}

Dissected buccal ganglia were maintained at $22^{\circ} \mathrm{C}$ using a Peltier-plate system and superfused continuously $(10 \mathrm{ml} / \mathrm{hr})$ with a physiological medium containing (in $\mathrm{mM}$ ): $\mathrm{NaCl} 460, \mathrm{KCl} 10, \mathrm{CaCl}_{2} 43.8, \mathrm{MgCl}_{2} 76.2$, $\mathrm{MgSO}_{4} 28$, Tris Buffer 10, $\mathrm{pH}$ 7.5. This high concentration in divalent cations was used to minimize spontaneous neuron firing activity as described (Humeau et al., 2001a). This medium corresponds to an extracellular $\left[\mathrm{Ca}^{2+} / \mathrm{Mg}^{2+}\right]$ ratio of 0.42 . To change $\left[\mathrm{Ca}^{2+}\right]_{\mathrm{e}}$, the extracellular $\left[\mathrm{Ca}^{2+} / \mathrm{Mg}^{2+}\right]$ ratio was modified by changing the concentrations of $\mathrm{CaCl}_{2}$ and $\mathrm{MgCl}_{2}$ but not that of $\mathrm{MgSO}_{4}$ (to keep the sulfates unmodified), as described previously (Doussau et al., 1998; Humeau et al., 2001a).

\section{Intraneuronal injection procedure}

Injection electrodes were pulled from glass tubing without a capillary and contained a silver wire to allow the electrophysiological monitoring of the impalement. Samples to be injected were mixed with a vital dye (fast green FCF, 10\% v/v; Sigma) as detailed elsewhere (Poulain et al., 1986; Doussau et al., 1998; Humeau et al., 2001a). The samples were air pressure-injected using a picopump PV820 (World Precision Instruments) under visual and electrophysiological monitoring. The injected volume was in the range of $1-2 \%$ of the cell body volume. Therefore, assuming a homogenous distribution of the injected material, the final intraneuronal concentration was $\sim 1 \%$ of that in the injection micropipette. After injection, the micropipette was removed carefully, and only presynaptic neurons with no alterations in action potentials and with membrane potentials between -60 and $-45 \mathrm{mV}$ were analyzed. The time of injection is denoted in most experiments as time zero. In several sets of experiments, we verified that the various buffers used for dissolving toxin samples had no effect on neurotransmitter release.

\section{Determination of IPSC amplitude and rise and decay times}

IPSC amplitude $(I)$ was determined as the peak current of recorded IPSC. The time to rise from 20 to $80 \%$ of the maximal IPSC amplitude was determined and denoted as "IPSC rise time." IPSC rise times were 
determined from at least 10 IPSCs recorded under the same experimental condition and averaged. The IPSC decay time constant was determined by fitting the IPSC with multi-exponential regression $I_{(\mathrm{t})}=$ $I_{\text {peak }}{ }^{*}\left[w_{1}{ }^{*} \exp ^{(-\mathrm{t} / \tau 1)}+w_{2}{ }^{*} \exp ^{(-\mathrm{t} / \tau 2)}\right]$, in which $\tau_{1}$ and $\tau_{2}$ are the time constants and $w_{1}$ and $w_{2}$ are the respective weights of the two components. In nearly all experiments analyzed, $w_{1} \rightarrow 1$ and $w_{2} \rightarrow 0$, indicating single exponential decay for IPSCs.

\section{Estimation of the quantal parameters: theoretical aspects}

In brief, consider the synaptic inputs attributable to the multiple contacts between a presynaptic neuron and its postsynaptic target and consider the three parameters: $q$, the amplitude of elementary postsynaptic response, $n$, the mean number of independent release sites, and $p$, the mean release probability at these sites. First, we assume that at each release site $p$ is the product of the output probability $p_{o}$ (i.e., the probability for a release-ready SV to fuse in response to presynaptic stimulus) and the probability $p_{A}$ that the site is eligible for release (i.e., that a primed SV is available for release) (Brown et al., 1976; Zucker, 1989; Quastel, 1997; Scheuss and Neher, 2001). Second, we assume that release probability and quantal size are uniform, that quanta sum up linearly, and that quantal release follows a simple binomial distribution. Therefore, following these assumptions, the average amplitude of IPSC is given by following equation:

$$
I_{\text {mean }}=n^{*} p_{o}{ }^{*} p_{A}{ }^{*} q,
$$

and the fluctuations of the responses around the mean have a variance:

$$
\operatorname{Var}=n^{*}\left(p_{o}^{*} p_{A}\right)^{*}\left[1-\left(p_{o}{ }^{*} p_{A}\right)\right]^{*} q^{2} .
$$

Similar to the ion channel analysis developed by Sigworth (1980), the analysis of the $\operatorname{Var}=f\left(I_{\text {mean }}\right)$ relationship when the release probability is experimentally modified permits an evaluation of the quantal parameters $n$ and $q$ (Quastel, 1997; Silver et al., 1998; Reid and Clements, 1999; Oleskevich et al., 2000; Clements and Silver, 2000; Meyer et al., 2001; Scheuss et al., 2002). Although this does not allow separate evaluations of $p_{A}$ and $p_{o}$ (Scheuss and Neher, 2001), modifications of the product $p_{o}{ }^{*} p_{A}=p$ can be detected. The simple binomial model of synaptic transmission predicts a parabolic relationship between Var and $f\left(I_{\text {mean }}\right)$. Indeed, this relationship can be reexpressed as a function of $I_{\text {mean }}$ :

$$
\text { Var }=q^{*} I_{\text {mean }}-(1 / n) * I_{\text {mean }}^{2},
$$

which can be fitted by a simple parabola of equation:

$$
\text { Var }=A^{*} I_{\text {mean }}-B^{*} I_{\text {mean }}^{2} \text {. }
$$

This allows determination of two parameters: $A$, the initial slope of the parabola, and $B$, the extent factor of the parabola. Parameter $A$ refers to $q$. However quantal variability (denoted as $C V_{q}, C V$ being the variation coefficient) also contributes to Var. Therefore, $A$ provides an overestimate of $q$ (Silver et al., 1998; Reid and Clements, 1999; Oleskevich et al., 2000, Scheuss and Neher, 2001):

$$
A=q^{*}\left(1+C V_{q}^{2}\right)
$$

Parameter $B$ refers to $1 / n$. However, probability parameters $p_{o}$ and $p_{A}$ are heterogeneous between the release sites at vertebrate synapses (Rosenmund et al., 1993; Murthy et al., 1997), and this is also likely to be the case at Aplysia synapses. Therefore, $1 / B$ underestimates $n$ according to equation:

$$
1 / B=n /\left[\left(1+C V_{p}^{2}\right)^{*}\left(1+\beta C V_{q \text { inter }}^{2}\right)\right],
$$

in which, $C V_{p}$ is the average variation of $p_{o}{ }^{*} p_{A}$ and $\beta C V_{q}$ inter is the fraction of quantal variance attributable to intersite variability (Brown et al., 1976; Silver et al., 1998; Meyer et al., 2001; Scheuss and Neher, 2001).

\section{Determination of $\mathrm{I}_{\text {mean }}$ and Var: practical aspects}

Stationary conditions. When under a given experimental condition the amplitude of the IPSCs was stable with time (i.e., during control recordings or when ACh release was stable after a change in extracellular $\left[\mathrm{Ca}^{2+} / \mathrm{Mg}^{2+}\right]$ or stimulation frequency), $I_{\text {mean }}$ and Var were calculated directly from the IPSC amplitude values determined in recording epochs of at least 25 IPSCs. Because background noise can contribute to Var, its variance, $\operatorname{Var}_{\text {noise }}$, was calculated from the baseline fluctuations in IPSC recordings, and subtracted from Var. Then the Var $=f\left(I_{\text {mean }}\right)$ plots were constructed.
Nonstationary conditions. When IPSC amplitude does not stabilize, determination of $I_{\text {mean }}$ and Var can be performed by nonstationary analysis, as reported previously for analysis of channel fluctuations during the course of evoked postsynaptic responses (Robinson et al., 1991; Traynelis et al., 1993). In essence, the aim of the nonstationary analysis is to determine $I_{\text {mean }}$ at each time of $I=f(t)$ plot. The result of subtracting the set of $I_{\text {mean }}$ to $I=f(t)$ plot generates the set of the fluctuations of $I$ data around $I_{\text {mean }}$, the variance of which is then determined. The accurate determination of $I_{\text {mean }}$ is critical for Var determination. In the earlier studies of Robinson et al. (1991) and Traynelis et al. (1993), $I_{\text {mean }}$ was approximated by the mean of fitting procedures or by averaging the recorded postsynaptic responses. We could not use this latter approach because each experiment had a unique time course, which could not be adjusted by simple mathematical equations. As an alternative, we estimated $I_{\text {mean }}$ at each time $t$ of the $I=f(t)$ plots as follows: $I=f(t)$ plots were submitted to local linear fitting using a modified built-in procedure of SigmaPlot5 software (SPSS Inc., Chicago, IL) based on least squared estimation of parameters. The local linear fitting was performed on a window of $w$ data (Fig. $1 A, B$, straight line into brackets) and repeated for the whole data range by moving the window by a step of one IPSC data. The mid-value of each local fit was considered as the estimate of $I_{\text {mean }}$ at the corresponding time. The set of $I_{\text {mean }}$ fits the $I=f(t)$ plot (Fig. $1 B$, solid line with small black dots). The result of subtracting the set of $I_{\text {mean }}$ to $I=f(t)$ plot $\left(I-I_{\text {mean }}\right)$ shows fluctuations around the zero level. $I-I_{\text {mean }}$ values are denoted by $\Delta I$ in Figure $1 C$. The variance, Var, of these fluctuations was then calculated in a window of $W$ data that was moving, with a step of one, along the whole data range to be analyzed. Var was corrected for background noise variance ( $\operatorname{Var}_{\text {noise }}$ ) (see above). Then, the Var $=f\left(I_{\text {mean }}\right)$ plots were constructed (Fig. $\left.1 D\right)$.

For each experiment analyzed, the width of the windows used for linear local fitting $(w)$ and the variance calculation $(W)$ needed to be adapted to the kinetics of the IPSC amplitude changes. Indeed, except in the case of a linear change in IPSC amplitude, when the window $(w)$ used for local linear fitting is too wide, the local fit deviates from the actual $I_{\text {mean }}$, and this results in an overestimation of Var (i.e., the problem of fitting a curve with a straight line); in contrast, when $w$ is too narrow, the local fit adapts to local fluctuations but leads to an underestimation of Var. The window width used for variance calculation, $W$, depended also on the kinetics of IPSC amplitude changes. Here, when the window is too wide, Var is calculated from the fluctuations in amplitude of IPSCs corresponding to very different mean amplitude, and the Var $=f\left(I_{\text {mean }}\right)$ plot is significantly distorted. To determine the $W$ and $w$ to be used, experiments in which either product of $p_{o}{ }^{*} p_{A}, n$ or $q$ was changed were simulated. They were submitted to the nonstationary analysis described above. The most appropriate $w$ and $W$ were determined as those minimizing the deviation of estimated quantal parameters from the parameters used for simulation. For the faster changes in IPSC amplitude (such as those caused by a rapid fall in extracellular $\left[\mathrm{Ca}^{2+} / \mathrm{Mg}^{2+}\right]$ ), a good compromise was to use $w=9$ or 11 data and $W=15-17$ (Fig. $1 E$ ). For slower IPSC changes, $w$ and $W$ were increased. Even in these conditions, there was a remaining deviation of overall estimate of $I_{\text {mean }}$ (as determined by local moving linear fitting) with the true $I_{\text {mean }}$ (as calculated by the equation that we used to simulate IPSC amplitude change). This is illustrated by the thick dotted or hatched line in Figure $1 C$. A consequence of this deviation was that the $\operatorname{Var}=f\left(I_{\text {mean }}\right)$ plots were fitted by parabolas (Fig. $1 D$, solid line) that were not exactly superimposable onto the theoretical calculated parabolas (Fig. $1 D$, dashed line). The uncertainty in the determination of parabola parameters $A$ and $B$ in the faster experiments was $\sim 10 \%$, whereas in slower experiments this error remained marginal.

\section{Parabola adjustment and determination of quantal parameters at Aplysia synapses}

Var $=f\left(I_{\text {mean }}\right)$ plots were fitted by Equation 4 constrained to pass the origin using a built-in procedure of SigmaPlot5 software. The coefficient of determination $r^{2}$ is reported in the Figures or corresponding text to indicate how good the fit is. $C V_{q}$ was not determined in this study because of the difficulty in distinguishing miniature events issuing from B4 or B5 presynatic neurons from the inhibitory inputs caused by the many other presynaptic neurons, and $C V_{p}$ was not estimated. Therefore, to provide insights on possible changes in $q$, we determined the parabola fitting parameter $A$ (see Eq. 5), and $B$ provides an estimate of $1 / n$ (see Eq. 6). According to Equation $1, p_{o}{ }^{*} p_{A}=I_{\text {mean }} /(n * q)$, and we calculated its approximation, $P$, according to the equation: 

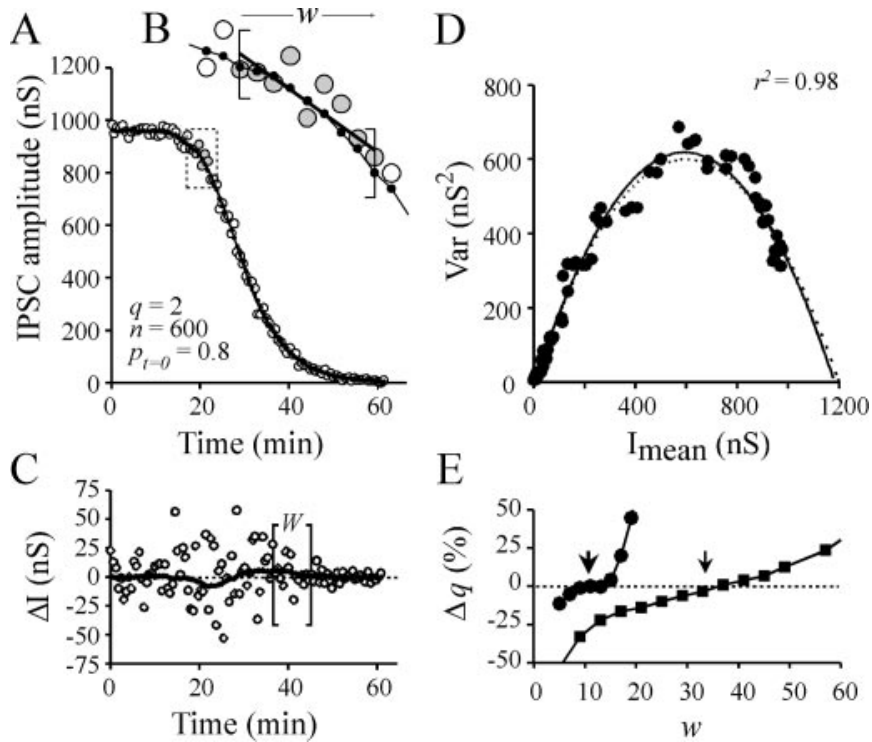

Figure 1. Determination of quantal parameters by nonstationary analysis as tested on a simulated experiment. $A$, IPSC amplitude $=f(t)$ values $(\bigcirc)$ were calculated as the product binomial $\left(n, p_{\mathrm{t}}\right)^{*} q$ in which $n=600$ sites and $q=2 \mathrm{nS}$. A sigmoid decrease of release probability $p=p_{o}{ }^{*} p_{A}$ with time, $t$, was simulated using equation $p_{\mathrm{t}}=0.8 /\left[1+\exp (-(t-20) /-3.5)^{0.5}\right]$. The solid line denotes the set of the $I_{\text {mean }}$ values determined at each $t$ (for details see Materials and Methods). $B$, Magnification of box shown in $A$. The window width used for local linear fitting $(w)$ is indicated within brackets (here $w=9$ ). Linear fit is indicated by solid straight line. The mid-values of the local linear fits are the estimates of $I_{\text {mean }}$ and are indicated by small dots on a solid line. $C$, Fluctuations in IPSC amplitude are approximated at each time $t$ of the $I=f(t)$ plot, by subtracting $I_{\text {mean }}$ from corresponding $I$ value $(\bigcirc)$. The $I_{\text {mean }}$ values determined by nonstationary analysis deviate from the true $I_{\text {mean }}$. This difference was determined by subtracting the determined $I_{\text {mean }}$ values from the predicted $I_{\text {mean }}$ and is represented by a solid thick line. The brackets denote the window width $W$ used for Var determination (here $W=16$ ). $D$, The corresponding Var $=f\left(I_{\text {mean }}\right)$ plot. Solid line denotes the adjustment of the data by simple parabola (Eq. 4). The predicted parabola (dashed line) was calculated using Equations 1 and 2 and the above-mentioned quantal parameters. The difference between both parabolas generates errors in the determinations of $q$ and $n$. The extent of this error can be minimized by optimizing the window width $(w)$ used for local linear fitting of IPSC $=$ $f(t)$. Error in estimation of $q$ is shown in $E[\Delta q(\%)]$ as a function of $w$, for two "experimental" conditions: when simulated IPSC amplitude decreases rapidly $\left(t_{1 / 2}=25 \mathrm{~min}\right)$ or slowly $\left(t_{1 / 2}=75 \mathrm{~min}\right)$. These situations are denoted by and $\mathbf{\square}$, respectively. For these two conditions, optimal $w$ values are indicated by arrows.

$$
P=I_{\text {mean }} *(B / A) .
$$

$P$ differs from actual values of average release probability $p_{o}{ }^{*} p_{A}$ by the contribution of quantal variability and probability variability (Eq. 5, 6).

If not stated otherwise, results are presented as means \pm SEM. When appropriate, the significance was tested by the paired or unpaired Student's $t$ test.

\section{RESULTS}

\section{Effect of the intraneuronal injection of lethal toxin from C. sordellii on evoked $\mathrm{ACh}$ release}

To restrict the action of the toxin to a single presynaptic element, LT82, which in vitro glucosylates recombinant Ras, Rac, Ral, and Rap but not Cdc42 and Rho, was pressure injected into either B4 or B5 cholinergic neurons to give a final intraneuronal concentration of $\sim 50 \mathrm{~nm}$. This induced a rapid decrease in IPSC amplitude, indicating inhibition of ACh release (Fig. $2 A-C$ ). No inhibition of $\mathrm{ACh}$ release was detected with the noninjected control neurons (Fig. $2 A, C$ ). In all experiments, the inhibitory
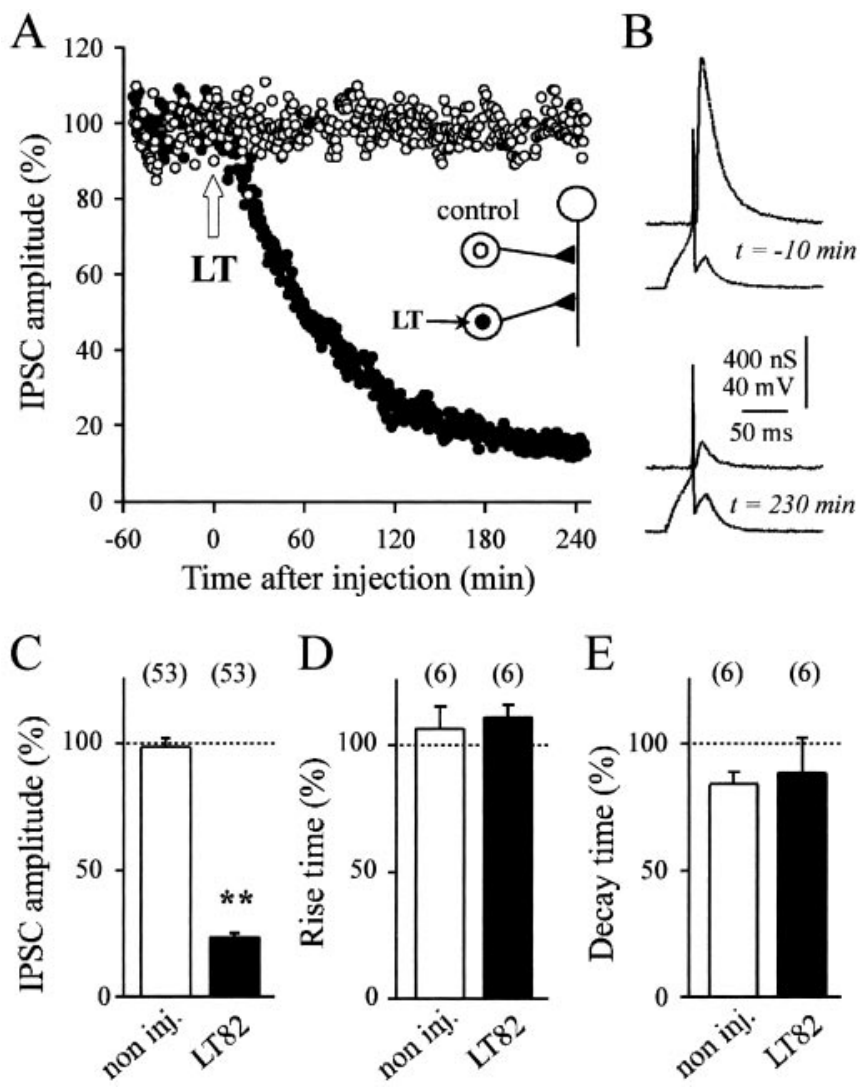

Figure 2. Inhibition of evoked ACh release by LT toxins that inactivate small GTPases. A, A representative experiment is illustrated. ACh release was evoked at identified synapses in the buccal ganglion of Aplysia californica. See inset for a schematic drawing of the neuronal connections. The amplitude of the IPSCs (percentage of average IPSC in control period) is plotted against time, before and after pressure injection of lethal toxin from $C$. sordellii $(L T)$ into one of the two presynaptic cholinergic neurons $(\Theta)$. The final concentration of LT in the cell body was $\sim 50 \mathrm{~nm}$. The second presynaptic neuron $(\bigcirc)$ was not injected. $B$, Recordings of presynaptic action potentials and IPSC at the time indicated before and after injection of LT. The mean IPSC amplitude $(C)$ and mean percentage changes in the IPSC rise time and decay time $(D, E)$ were determined $180 \mathrm{~min}$ after the time of toxin injection for noninjected (open bars) and LT82-injected ( filled bars) neurons and normalized with respect to the mean values observed before the time of toxin injection. The number of experiments is indicated. $C-E, * *$ denotes significant difference $(p<0.001)$ as compared with the controls; other comparisons are nonsignificant $(p>0.5)$.

action of LT manifested after an average delay of $15.2 \pm 3.9$ (SD, $n=53)$ min after the injection. This may represent the time needed for LT molecules [molecular weight (MW) $\sim 250 \mathrm{kDa}$ ] to diffuse up to the nerve terminals that are distant by $300-500 \mu \mathrm{m}$ from the presynaptic soma. This delay is comparable with that (5-10 min) observed for tetanus and botulinum neurotoxins (MW $\sim 150 \mathrm{kDa}$ ) at the same synapses (Poulain et al., 1988; Schiavo et al., 1992).

Typical recordings, illustrated in Figure $2 B$, exhibit no detectable alteration in the action potentials recorded in the injected neurons at a time when IPSC amplitude was strongly depressed. This suggests that the inhibitory action of LT on ACh release does not result from an alteration in presynaptic membrane excitability. We also found no change in either the IPSC rise or decay time after LT had exerted its blocking action (Fig. 2D,E). This latter finding indicated that release kinetics and synchronization of released quanta remained unchanged after LT action. 


\section{Blocking of ACh release needs an LT intact catalytic site}

The impressive blocking action of LT (Fig. $2 A, C$ ) was comparable, on a molar basis, to that produced by intraneuronal application of tetanus or botulinum neurotoxins (Poulain et al., 1988; Schiavo et al., 1992). This raised the question of whether the blocking action of LT was causally linked to its well characterized glucosylating enzymatic activity. Glucosylation of small GTPases by LT involves an enzymatic domain localized in the N-terminal region of the toxin (for review, see Busch and Aktories, 2000). A recombinant polypeptide (amino acids 1-546, denoted as LT82 $\mathrm{NH} 2$ ) was produced in E. coli. Similar to its parent holotoxin, this peptide retained the ability to glycosylate mammalian recombinant Rac, Ras, Ral, and Rap, but neither Rho nor Cdc42, in vitro (Fig. 3A, compare the top two autoradiograms). Intraneuronal application of LT82 NH2 (50 nM, final intrasomatic concentration) also blocked $\mathrm{ACh}$ release in a manner comparable to the holotoxin (Figs. $2 C, 3 B$ ) (no significant difference: $p=0.33$ ). In contrast, when a double mutation (aspartate to alanine exchange at positions 286 and 288) was introduced to abolish $\mathrm{Mn}^{2+}$ coordination and UDP-glucose binding (Busch et al., 1998), the recombinant peptide (Fig. 3, LT82 NH2 mutant) had no glucosyltransferase activity on recombinant GTPases, in vitro (Fig. $3 A$, bottom panel), and no blocking action on neurotransmitter release when applied intraneuronally (50 nM, final intrasomatic) (Fig. 3B, white bar).

\section{LT glucosylates small GTPases in Aplysia}

Figure $4 A$ shows a Western blot analysis of the small GTPases present in Aplysia nerve tissue. These immunoreactivities were detected using specific antibodies raised against members of the Rho and Ras families and correspond to proteins migrating with an apparent molecular weight of $20-30 \mathrm{kDa}$ (data not shown). They cannot be strictly assigned as being Rho, Rac, Cdc42, Ras, Ral, or Rap. Indeed, because of possible divergent evolution of Rho and Ras GTPases, cross-reactivities of the mammalian antibodies with several GTPases cannot be excluded.

The intraneuronal targets affected by LT were examined by determining incorporation of ${ }^{14} \mathrm{C}$-glucose into Aplysia proteins. Because UDP-glucose, the LT cosubstrate, cannot cross the plasma membrane, these experiments were performed on Aplysia neuronal tissue fractions. Fractions containing either soluble (i.e., mostly cytosolic) or insoluble (i.e., membrane associated) protein material were treated with LT82 or LT9048 (5 $\mu \mathrm{g} / \mathrm{ml}$ for $1 \mathrm{hr})$ in the presence of $7 \mu \mathrm{M}$ UDP- ${ }^{14} \mathrm{C}$-glucose, and then proteins were separated by SDS-PAGE. Figure $4 B$, (first, second, fifth, and sixth lanes from left) shows that ${ }^{14} \mathrm{C}$-glucose incorporation was detectable only in proteins of $18-30 \mathrm{kDa} \mathrm{MW}$ and may correspond to the glucosylation of the Aplysia monomeric GTPases revealed by Western blotting (Fig. 4A).

\section{Blocking activity of LT on ACh release is causally linked to glucosylation of Rac}

Substitution of glucose in the nucleotide-sugar by other sugar moieties inhibits the glucosylation reaction (Hofmann et al., 1998; Busch et al., 2000). Moreover, the nucleotide moiety is also important: for example, UDP-mannose but not GDP-mannose competitively inhibits Ras glucosylation, in vitro (Busch et al., 2000). We found that incubation of $10 \mathrm{~mm}$ UDP-mannose completely prevented LT-induced incorporation of ${ }^{14} \mathrm{C}$-UDP-glucose into protein extracts of Aplysia (Fig. 4B, third, fourth, seventh, and eighth lanes from left) or recombinant small GTPases (Fig. $5 A$,
A
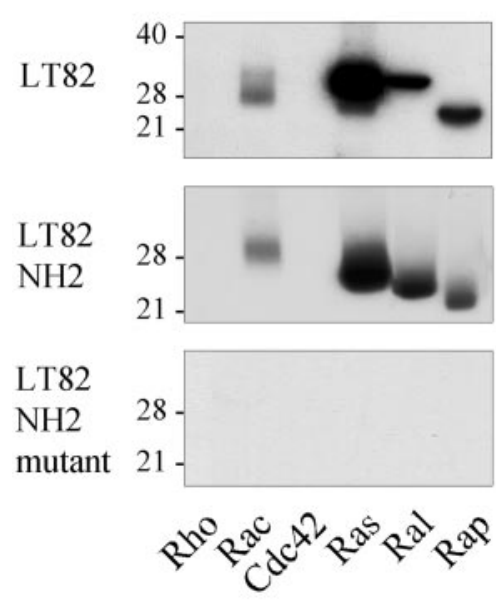

B

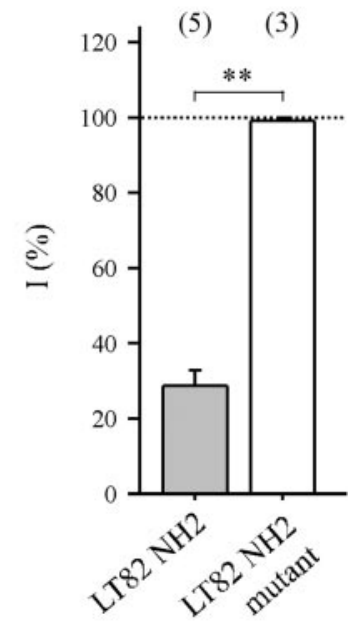

Figure 3. Mutations in catalytic domain of LT82 abolish both GTPaseglucosylating and ACh release-blocking activities. $A$, Protein substrate specificity of glucosylation by LT82 (top panel), recombinant LT82 fragment (amino acids 1-546) containing an intact catalytic domain (middle panel; LT82 NH2) or a D to A exchange at positions 286 and 288 (bottom panel; LT82 NH2 mutant). Recombinant GTPases (1 $\mu \mathrm{g}$ of each) were incubated with LT or fragments $(5 \mu \mathrm{g} / \mathrm{ml})$ in the presence of UDP- ${ }^{14} \mathrm{C}-$ glucose for $60 \mathrm{~min}$ at $37^{\circ} \mathrm{C}$. Labeled proteins were analyzed by SDSPAGE and autoradiography. Position of molecular weight markers is indicated. $B$, The effect of recombinant fragments on ACh release. Same presentation of the data as in Figure $2 C$.** denotes significant difference $(p<0.001)$.

lane 2). In good agreement with this observation, we observed that intraneuronal coapplication of UDP-mannose and LT82 (1 $\mathrm{mm}$ and $50 \mathrm{~nm}$ final, respectively) did not block ACh release (Fig. $5 B$, second bar from left). This provided further support for a causal link between glucosylation of GTPases and inhibition of exocytosis. Moreover, when UDP-mannose (1 mM) was injected into neurons preinjected with LT82, UDP-mannose immediately froze the blocking action of LT82 (a representative experiment of three in shown in Fig. 5C), but no recovery of ACh release was observed (i.e., for at least $6 \mathrm{hr}$ after injection of UDP-mannose).

Interestingly, we found that the glucosylation reaction could be assigned more selectively to Rac by using ADP- or TDP-glucose as competitive inhibitors for UDP-glucose. Indeed, when the glucosylation reaction was performed, in vitro, in the presence of $10 \mathrm{~mm}$ ADP-glucose (data not shown) or TDP-glucose (Fig. 5A), ${ }^{14} \mathrm{C}$-glucose incorporation into Ras-related proteins (Ras, Rap, and, at a lesser extent, Ral) was markedly reduced, whereas glucosylation of Rac was mostly unaffected. Therefore, intraneuronal application of TDP-glucose (10 mM, final) with LT82 (50 $\mathrm{nM}$, final) was used to minimize intraneuronal glucosylation of Ras, Rap, and Ral. In this experimental condition, we observed that the release of $\mathrm{ACh}$ was blocked to a similar extent as that produced by LT82 alone (Fig. 5B; compare first and fourth bar from left).

To determine whether the residual glucosylation of Ral participates in the LT82-induced blockage of ACh release, we used LT9048, which has hardly any effect on Ral but efficiently glucosylates Rac, Ras, and Rap as LT82, but also Cdc42 (Fig. 5A, fourth lane from left). The blocking action of LT9048 (50 nM, final) was comparable to that induced by injection of LT82 (Fig. $5 B$, fourth bar from left). This indicated that glucosylation of Ral by LT82 does not contribute to the LT-induced blockage of ACh 
A

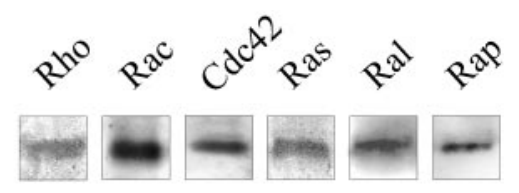

B

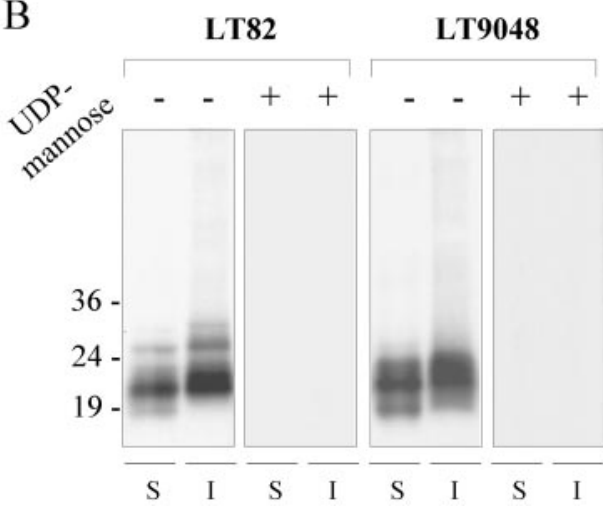

Figure 4. LT induces glucosylation of GTPases in Aplysia. A, Immunochemical detection of small GTPases present in Aplysia nerve tissue. Total protein homogenates $(20 \mu \mathrm{g})$ were subjected to gel electrophoresis and transferred to nitrocellulose sheets, and the GTPases were detected using anti-Rho, anti-Rac1, anti-Cdc42, anti-Ras, anti-Ral, and anti-Rap antibodies. B, Samples of Aplysia nerve tissue fractions ( $S$, soluble; $I$, insoluble) containing $100 \mu \mathrm{g}$ of neuronal proteins were incubated with LT82 or LT9048 (5 $\mu \mathrm{g} / \mathrm{ml}$ each) and UDP- ${ }^{14} \mathrm{C}$-glucose alone (denoted as -$)$ or in the presence of $10 \mathrm{~mm}$ UDP-mannose (denoted as + ), submitted to SDS-PAGE, and autoradiographed. The position of molecular weight markers is indicated.

release. To summarize, these combinations of treatments and toxins indicate that the glucosylation of Rac is sufficient to explain the inhibitory action of LT on ACh release.

The second part of the study was aimed at determining the release process altered by LT (i.e., implicating Rac-mediated pathway). Previously, we showed that $\mathrm{ACh}$ release can recover from near total inhibition to initial values in $\sim 1 \mathrm{sec}$ when sustained high-frequency stimulations $(>10 \mathrm{~Hz})$ are applied to poisoned nerve terminals (Doussau et al., 2000). This time duration is shorter than the average SV cycle in active synaptic buttons $(\sim 11 \mathrm{sec})$ and average residency time of docked SVs at active zones $(\sim 2-5 \mathrm{sec})$ (Klingauf et al., 1998; Murthy and Stevens, 1999). Therefore, the SVs participating in ACh release recovery are likely to be recruited in a pool that is already tethered or docked at the active zone but cannot undergo fusion. Therefore, LT action may disrupt a membrane step of the exocytotic process. To investigate this possibility, we analyzed the possible modifications of the quantal release parameters by LT.

\section{Determination of quantal size and number of active release sites at the identified cholinergic synapses in the buccal ganglion of Aplysia}

To estimate the quantal size, $q$, and number of functional release sites, $n$, we generated IPSC variance versus mean plots (see Materials and Methods) by submitting buccal ganglion synapses to protocols aimed at changing average release probability, (i.e., the product $p_{o}{ }^{*} p_{A}$ ) and thus ACh release. Average product $p_{o}{ }^{*} p_{A}$ was altered by two different manipulations. The first one involved a change in the extracellular $\left[\mathrm{Ca}^{2+} / \mathrm{Mg}^{2+}\right]$ ratio and was aimed at changing the effectiveness of an action potential in activating a release site (i.e., to alter mainly but not exclusively $p_{o}$ ). The second manipulation was based on changes in stimulation fre- quency inducing a variable degree of depression (Silver et al., 1998) and was expected to affect mainly but not exclusively $p_{A}$. Indeed, the probability for a site to be filled with a SV ready for release depends on the balance between the release rate and the replenishing kinetics of the release site and also from the priming mechanisms that allow a docked SV to become fully releasable.

In the first series of seven experiments, the release probability was changed by manipulating the extracellular $\left[\mathrm{Ca}^{2+} / \mathrm{Mg}^{2+}\right]$ ratio. In the first part of the experiments, we analyzed (stationary analysis) the fluctuations in amplitude of IPSCs during stable epochs of $\sim 30 \mathrm{~min}$ after the ganglia had been superfused with medium containing different $\left[\mathrm{Ca}^{2+} / \mathrm{Mg}^{2+}\right]$ ratios (five distinct levels between 2.1 and 0.14 ) (Fig. 6A). In the second part of these experiments, nonstationary analysis was performed on the fluctuations in IPSC amplitude during the reduction in ACh release caused by a fast transition between high (2.1) and low (0.14) extracellular $\left[\mathrm{Ca}^{2+} / \mathrm{Mg}^{2+}\right]$ ratios (Fig. $6 B$ ). As shown in Figure 6, $C$ and $D$, the $A$ and $B$ parameters of the parabolas (Eq. 4) adjusting the $\operatorname{Var}=f\left(I_{\text {mean }}\right)$ plots were the same for both protocols (compare black-filled and open bars). The duration of the second protocol (45-60 min) was short enough to be performed twice on the same neuron, before and after injection of LT (see below).

In a second series of experiments, we attempted to modify product $p_{o}{ }^{*} p_{A}$ by changing the rate of stimulation. Increasing the stimulation rate resulted in synaptic depression (Fig. $6 E_{1}$ ), which is thought to reflect synaptic vesicle depletion at release sites. After stabilization of ACh release in each stimulation condition, the amplitude of fluctuation in IPSC around $I_{\text {mean }}$ was determined using stationary analysis. The Var $=f\left(I_{\text {mean }}\right)$ plots (Fig. $\left.6 E_{3}\right)$ were satisfactorily fitted $\left(r^{2}>0.90\right)$ by a simple parabola (Eq. 4). This graphically confirmed our assumption (see above) that when the rate of stimulation is increased, release probability is diminished. Figure 6, $C$ and $D$ (gray-filled bars), shows that the $A$ and $B$ parameters determined by this protocol were not significantly different from those determined by manipulating extracellular $\left[\mathrm{Ca}^{2+} / \mathrm{Mg}^{2+}\right]$ ratios to change product $p_{o}{ }^{*} p_{A}$ (Fig. 6C,D, compare the gray-filled bars with open and blackfilled bars).

The average $A$ values (Fig. $6 C$ ) as determined by these three procedures indicate a quantal size, $q$, of $\sim 2.5-2.8 \mathrm{nS}$ at the studied synapse. This value overestimates true $q$ because quantal variability $\left(C V_{q}\right)$ contributes to IPSC fluctuations (Eq. 5). Nevertheless, the $A$ value is comparable to the uncorrected $q$ values determined previously (1.5-2 nS) at the same Aplysia synapse using a different approach (Simonneau et al., 1980; Poulain et al., 1986). The parameter $B$ (expressed as $1 / B$ in Fig. $6 D$ to refer to $n$ ) suggests that the number of independent release sites at which quantal release can take place is between 400 and 500 at the studied Aplysia synapse. Because variability in release probability $\left(C V_{p}\right)$ and intersite quantal variability $\left(C V_{q}\right.$ inter $)$ were not determined, $1 / B$ is likely to underestimate $n$ (Eq. 6).

\section{Quantal parameters determined by manipulating extracellular $\left[\mathrm{Ca}^{2+} / \mathrm{Mg}^{2+}\right]$ after LT action}

To determine which of the quantal parameters were modified and accounted for the decrease in IPSC amplitude that characterizes LT action, the fast change in extracellular $\left[\mathrm{Ca}^{2+} / \mathrm{Mg}^{2+}\right]$ protocol was applied before and after LT82 had significantly inhibited $\mathrm{ACh}$ release. Figure $7 A$ shows a typical experiment from a series 
A

B
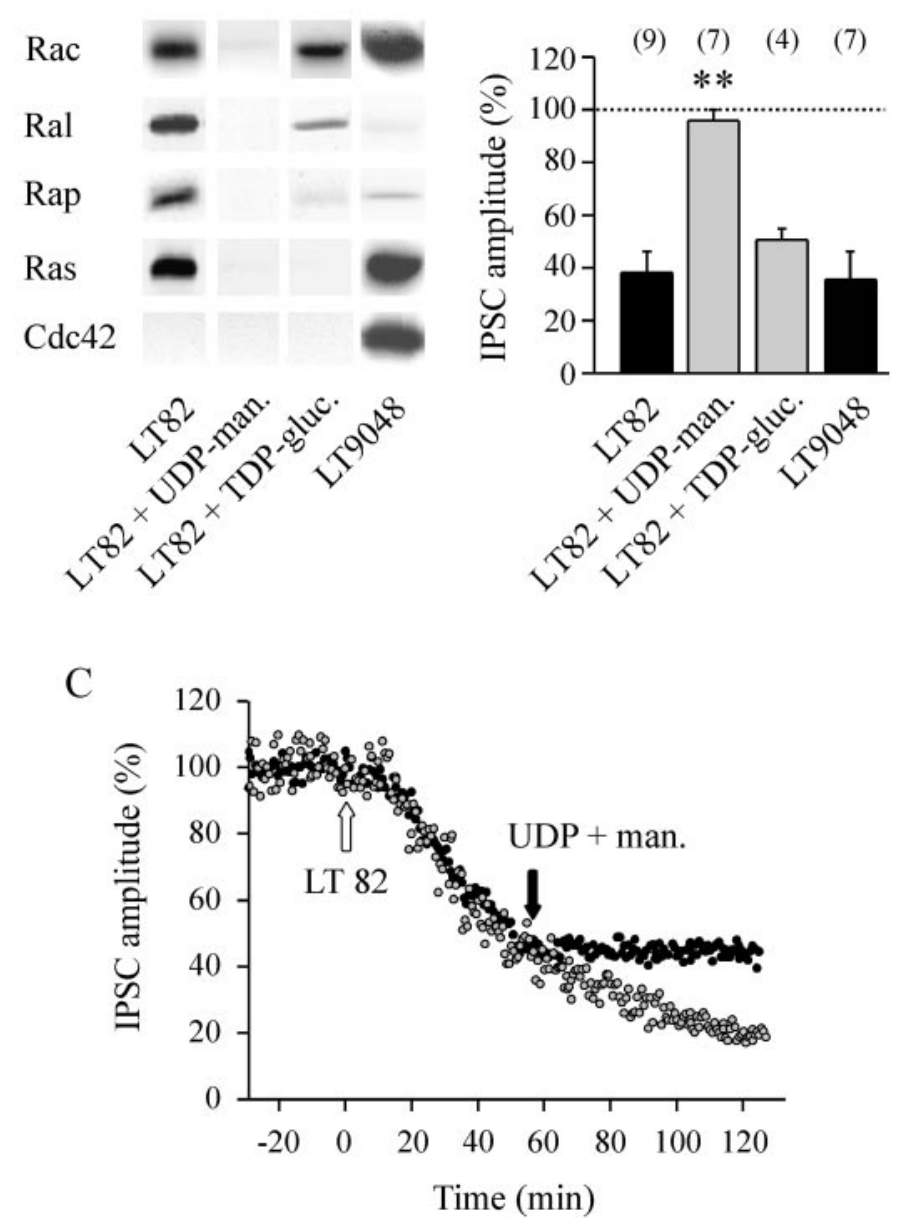

Figure 5. Glucosylation of Rac and inhibition of ACh release by LT. A, The substrate specificity of LT82 and LT9048 was determined as described in Figure $3 A$ except that in vitro glucosylation was performed in the absence or presence of glucosylation competitors: $1 \mathrm{~mm}$ unlabeled UDP-mannose (UDP-man.) or $10 \mathrm{~mm}$ unlabeled TDP-glucose (TDPgluc.). The position of molecular weight markers is indicated. $B$, The ACh release inhibition determined $90 \mathrm{~min}$ after injection of LT82 alone (50 nM, final intrasomatic) or together with UDP-mannose (1 mM final) or TDPglucose (10 mm final), or LT9048 (50 nM final). Data are expressed as a percentage of the average IPSC amplitude determined before injection. The horizontal dashed line means no inhibition. The number of experiments in each conditions is indicated. $* *$ denotes significant difference $(p<0.001)$ as compared with the other conditions. All other comparisons are nonsignificant. $C$, Same kind of experiment as in Figure $2 A$, except that both presynaptic neurons were injected with LT82 (50 nM, final, white arrow), but one of them (-) was later injected with UDP-mannose $(1 \mathrm{~mm}$, final) at the time denoted by the black arrow (similar results were obtained in 5 experiments).

of five. To minimize the difficulty in analyzing the combined blocking action of LT82 and the reduction in synaptic efficacy caused by $\left[\mathrm{Ca}^{2+} / \mathrm{Mg}^{2+}\right]$ change, the protocol was applied at a time when the LT-induced block was at least $80 \%$ (on average by 84\%) (Fig. 8A). During the high to low $\left[\mathrm{Ca}^{2+} / \mathrm{Mg}^{2+}\right]$ transition protocol (40-60 $\mathrm{min})$, we determined that the blockage caused by LT82 was $11.7 \pm 2 \%(\mathrm{SEM})$ as compared with the $91.8 \pm 1 \%$ decrease in IPSC amplitude observed when $\left[\mathrm{Ca}^{2+} / \mathrm{Mg}^{2+}\right]$ was lowered from 2.1 to 0.14 . The corresponding nonstationary analysis of fluctuations in IPSC amplitude and Var $=f\left(I_{\text {mean }}\right)$ plots is shown in Figure 7, $B$ and $C$. After LT had blocked ACh release, the $\operatorname{Var}=f\left(I_{\text {mean }}\right)$ relationship still appeared parabolic (Figs. $7 D$,
$8 B)$. The initial slope of the parabola, $A$, remained unmodified (Figs. $7 D, E, 8 C$ ), suggesting that quantal size, $q$, was not changed. However, if the studied synapse is saturating, it is conceivable that small changes in the presynaptic component of $q$ (SV content) may not have been detected.

The relationship between $\mathrm{ACh}$ release and extracellular $\mathrm{Ca}^{2+}$ was examined by plotting the $I=f\left(\left[\mathrm{Ca}^{2+} / \mathrm{Mg}^{2+}\right]\right)$. To highlight possible changes in this relationship, the IPSC amplitude values were normalized to the amplitudes observed at the lowest extracellular $\left[\mathrm{Ca}^{2+} / \mathrm{Mg}^{2+}\right]$ used. However, no apparent modification could be found after LT treatment compared with the control period (Fig. $8 D$ ). In all experiments, we observed that the portion of the parabola depicted in the $\operatorname{Var}=f\left(I_{\text {mean }}\right)$ plots during decreasing extracellular $\left[\mathrm{Ca}^{2+} / \mathrm{Mg}^{2+}\right]$ started at the same initial average probability as that observed before applying LT (Figs. $7 E$, $8 B$, straight lines), thereby indicating that average product $p_{o}{ }^{*} p_{A}$ was unchanged. Moreover, the relationship between $P$ (which refers to product $p_{o}{ }^{*} p_{A}$, Eq. 7) and extracellular $\left[\mathrm{Ca}^{2+} / \mathrm{Mg}^{2+}\right]$ did not significantly change before and after LT (Fig. $8 F$ ). This suggests that the coupling between $\mathrm{Ca}^{2+}$ influx and exocytosis is unlikely to be altered by LT action.

After LT, the only difference that we detected was the decrease in parabola parameter $B$. Indeed, $1 / B$ (Fig. $8 E$ ) was reduced to an extent similar to the reduction in mean IPSC amplitude induced by LT (Fig. 8A). This suggests that the blocking action of LT action is caused by a diminution in $n$, the number of active release sites.

Intracellular application of the $\mathrm{Ca}^{2+}$-buffer EGTA has been shown to interfere with LT action (Doussau et al., 2000). Moreover, in rat basophilic leukemia (RBL) mast cells, LT application as well as expression of dominant-negative Rac results in the disruption of $\mathrm{Ca}^{2+}$ mobilization from internal stores (Djouder et al., 2000; Hong-Geller and Cerione, 2000). Hence, we cannot exclude the possibility that the change in extracellular $\left[\mathrm{Ca}^{2+} / \mathrm{Mg}^{2+}\right]$ protocol used above for determining the quantal parameters did not interfere with LT inhibitory action leading to false deduction that only $n$ was modified. To test this possibility, we next analyzed the variance-mean plots generated by changing the stimulation frequency to alter average product $p_{o}{ }^{*} p_{A}$, as described in Figure $6 E$.

\section{Quantal parameters determined by changing stimulation frequency after LT action}

The "change in stimulation rate" protocol was applied before and after LT82 had inhibited ACh release (Fig. 9A). In preliminary experiments, we noticed that a significant inhibitory effect of LT developed during the long duration needed for this protocol (120-180 min to collect enough data for variance determination). To avoid this problem, the effects of LT were stopped by intraneuronal injection of UDP-mannose (1-10 mM, final) after that ACh release was inhibited by $\sim 80 \%$ (Figs. $9 A, 10 A$ ). Because of the technical difficulty in injecting the same neuron twice without trauma, only four experiments could be analyzed. The "stimulation rate protocol" was performed $\sim 60$ min after the UDPmannose injection to verify that LT action was indeed stopped. Fluctuations in IPSC amplitude were analyzed before (control) and after LT injection by the stationary procedure (Fig. 9B,C).

The $\operatorname{Var}=f\left(I_{\text {mean }}\right)$ plots were well fitted $\left(r^{2}>0.90\right)$ by a simple parabola (Figs. $9 D, E, 10 B$ ). As expected, the parabola parameter $A$ was not significantly modified by LT treatment, confirming that quantal size is unchanged (Fig. 10C). Here also, the $\operatorname{Var}=f\left(I_{\text {mean }}\right)$ plots depicted the same portion of parabola (Figs. 9D, 10B) before and after blockage of $\mathrm{ACh}$ 
$\mathrm{A}_{1}$

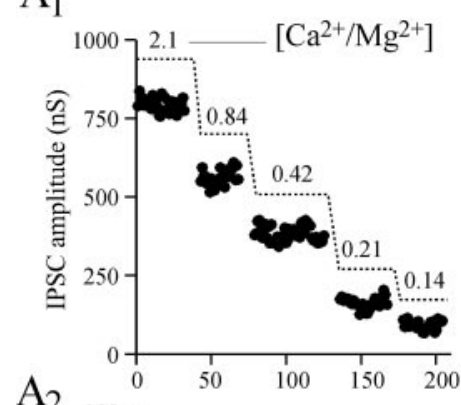

$\mathrm{A}_{2}$
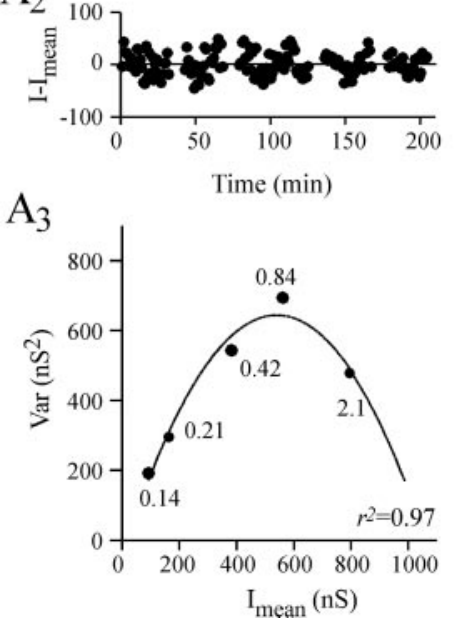

$\mathrm{B}_{1}$
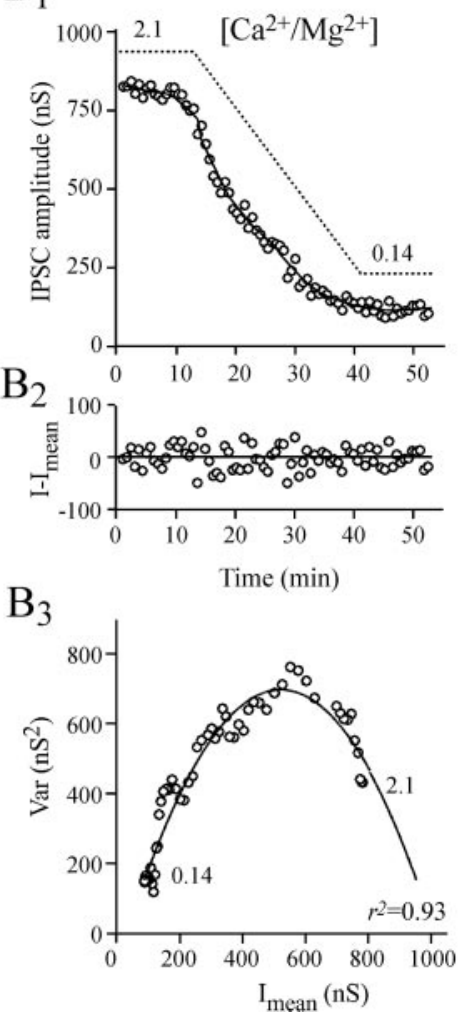

$\mathrm{C}$

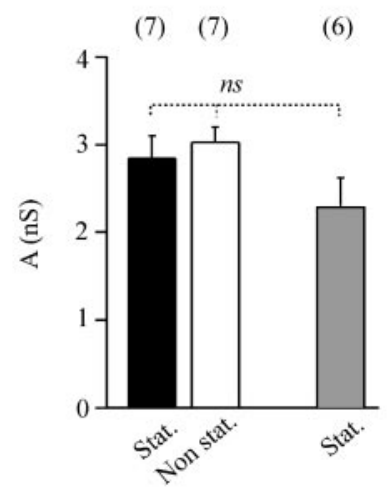

$\left[\mathrm{Ca}^{2+} / \mathrm{Mg}^{2+}\right]$ Stim. rate

$\mathrm{D}$

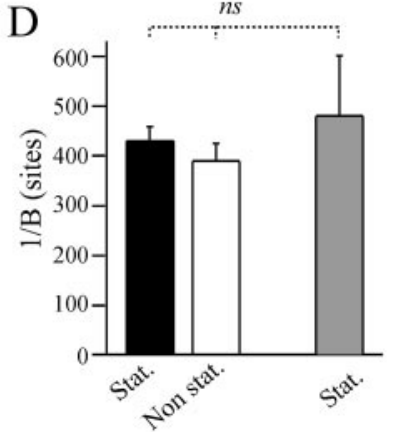

$\mathrm{E}_{1}$

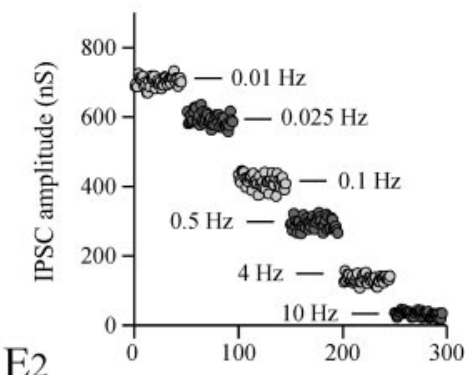

E2

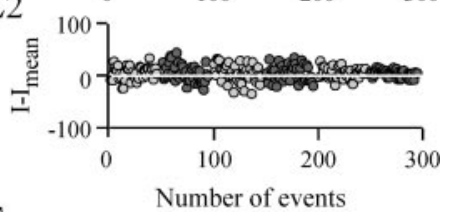

$\mathrm{E}_{3}$

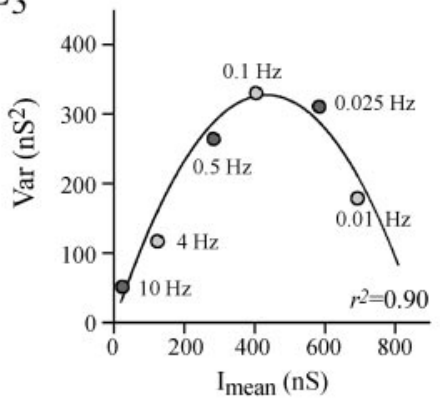

Figure 6. Stationary and nonstationary analysis of the fluctuations in IPSC amplitude when release probability is modified. The experiment illustrated in $A$ and $B$ is representative of a series of seven performed under the same experimental conditions. The Aplysia ganglion was superfused with physiological medium containing modified extracellular $\left[\mathrm{Ca}^{2+} / \mathrm{Mg}^{2+}\right]$ (as indicated in $A_{1}$ and $B_{1}$ ) to change release probability. $A_{1}$, The $I=f(t)$ plot reporting IPSC amplitude $(I)$ measured after stabilization or evoked ACh release at the indicated extracellular $\left[\mathrm{Ca}^{2+} / \mathrm{Mg}^{2+}\right] . B_{l}, \mathrm{The} I=f(t)$ plot during transition between high and low extracellular $\left[\mathrm{Ca}^{2+} / \mathrm{Mg}^{2+}\right] . A_{2}, B_{2}$, The result of subtracting $I_{\text {mean }}$ from the corresponding $I$ as determined by stationary $(A)$ or nonstationary analysis using a window for local linear fitting $w=9$, and variance window width $w=16(B)$. For details, see Materials and Methods and Figure $1 . A_{3}, B_{3}$, The corresponding $\operatorname{Var}=f\left(I_{\text {mean }}\right)$ plots. The solid line denotes the approximation of the data by a simple parabola using Equation 4. The regression coefficients $r^{2}$ are indicated to indicate how good the fits are. $A$ and $B$ are taken from the same experiment in which the corresponding values of $A$ that refer to $q$ are $2.91 \mathrm{nS}\left(A_{3}\right)$ and $2.83 \mathrm{nS}\left(B_{3}\right)$ and $1 / B$ that refer to $n$ are 426 sites $\left(A_{3}\right)$ and 389 sites $\left(B_{3}\right)$. $C, D$, Averaged parabola parameters $A$ and $1 / B$. Black-filled bars, open bars, and gray-filled bars refer to $A$ and $1 / B$ determined by stationary and nonstationary analysis when extracellular $\left[\mathrm{Ca}^{2+} / \mathrm{Mg}^{2+}\right]$ was changed as described in $A$ and $B$ and when stimulation rate was modified as described in $E$, respectively. These two experimental conditions are denoted as $\left[\mathrm{Ca}^{2+} / \mathrm{Mg}^{2+}\right]$ and Stim. rate. The number of experiments is indicated, and ns denotes nonsignificant difference. $E$, To change release probability, presynaptic neurons were submitted to various stimulation frequencies. A representative experiment of a series of six is illustrated. IPSC amplitudes from epochs of 50 recordings at the indicated stimulation frequency were reported against the total number of IPSCs analyzed. $E_{2}$, Using stationary analysis, the fluctuation of IPSC around $I_{\text {mean }}$ was determined. $E_{3}$, The corresponding Var $=f\left(I_{\text {mean }}\right)$ plot. The solid line denotes the parabola adjusted to the plot using Equation 4.

release by LT. Neither the shape of the $I_{\text {mean }}=f$ (stimulation interval) plots (Fig. 10D) nor the relationships between $P$ and the stimulation interval were modified after LT injection, as compared with controls (Fig. 10F). We could not explore the responsiveness of the synapse to very high frequency because at a stimulation rate over $10 \mathrm{~Hz}$, LT-induced block is relieved (Doussau et al., 2000). These findings confirm that our deduction made above that the product $p_{o}{ }^{*} p_{A}$ is not changed by LT action. Here also, the only parameter modified after LT was $B$ (Fig. 10E), indicating that $n$ is reduced by LT action.

\section{Variance to mean relationship during LT-induced blockage of $\mathrm{ACh}$ release confirms a reduction in the number of release sites}

If LT82-induced blockage of ACh exocytosis is caused by a decrease in $n$, this should also manifest as a linear relationship between $I_{\text {mean }}$ and Var in the Var $=f\left(I_{\text {mean }}\right)$ plots made by nonstationary analysis of IPSC amplitude fluctuations during the $\mathrm{ACh}$ release blockage produced by LT injection. Indeed, when
IPSC amplitude changes as the result of a reduction of $n$, Var should decrease linearly with $I_{\text {mean }}$ according to equation:

$$
\operatorname{Var}=\left(1-p_{o}^{*} p_{A}\right)^{*} q^{*} I_{\text {mean }} .
$$

A fall in IPSC amplitude caused by a change in the product $p_{o}{ }^{*} p_{A}$ should be described by Equation 3, which is a parabola (see Eq. 4 ), similarly as this has been illustrated above when $p_{o}{ }^{*} p_{A}$ was experimentally modified by distinct procedures. After progressive $q$ changes, the Var $=f\left(I_{\text {mean }}\right)$ relationship should be described by a quadratic function of positive curvature of equation:

$$
\operatorname{Var}=\left[\left(1-p_{o}{ }^{*} p_{A}\right) /\left(n^{*} p_{o}{ }^{*} p_{A}\right)\right]^{*} I_{\text {mean }}{ }^{2} .
$$

Data were submitted to a nonlinear regression analysis using the quadratic function $\operatorname{Var}=a^{*} I_{\text {mean }}+b^{*} I_{\text {mean. }}^{2}$ Indeed, this procedure avoids any a priori on the linearity or nonlinearity of the $\operatorname{Var}=f\left(I_{\text {mean }}\right)$ relationship. A linear slope should manifest with $b=0$ and $a>0\left(\operatorname{Var}=a^{*} I_{\text {mean }}\right)$. If $a=0$ and $b>0$, Var $=$ 
A
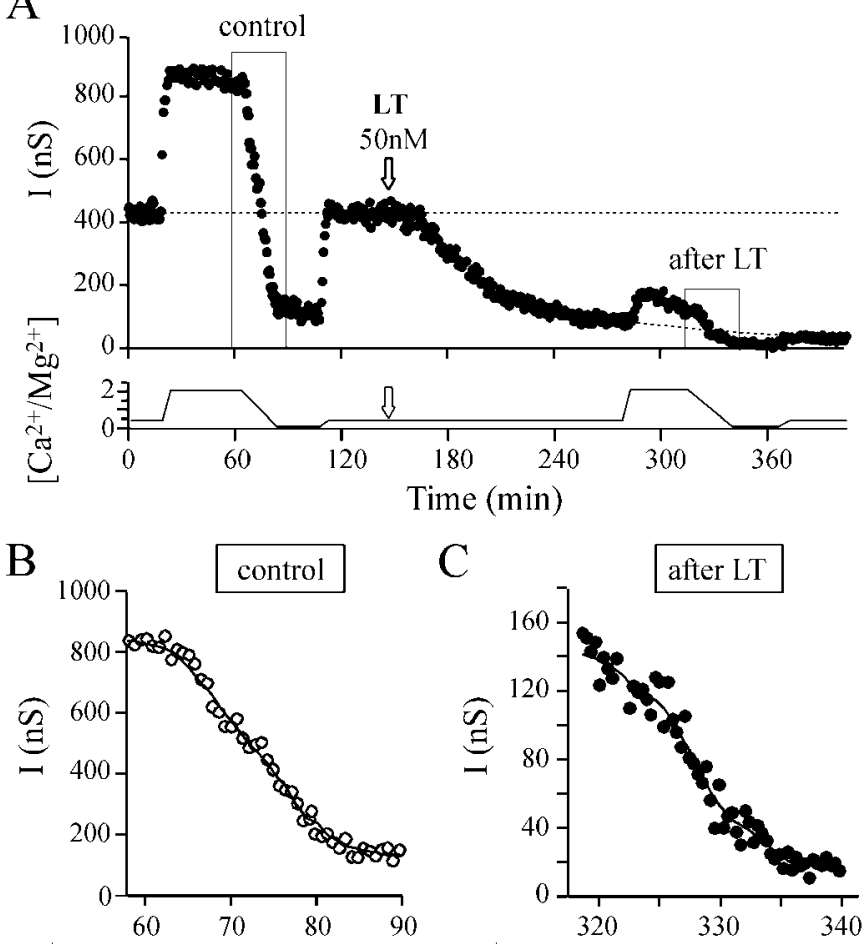

C after LT
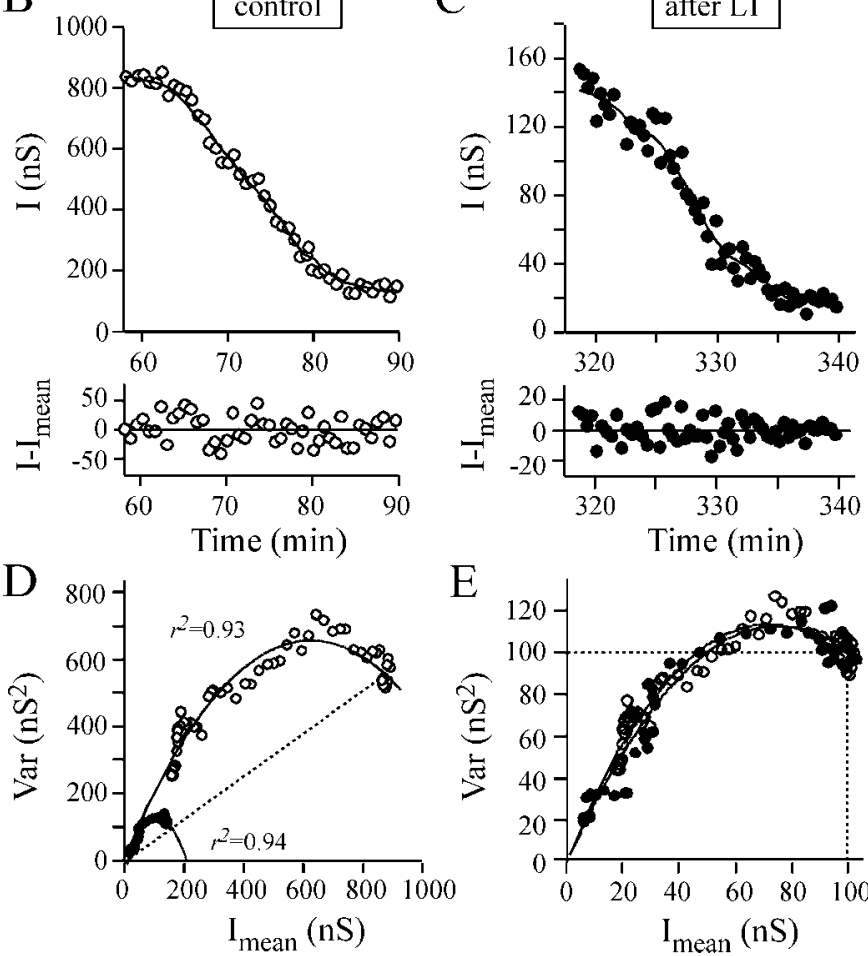

Figure 7. The effect of changing extracellular $\left[\mathrm{Ca}^{2+} / \mathrm{Mg}^{2+}\right]$ before and during LT action. The experiment illustrated is representative of a series of five performed under the same experimental conditions. $A$, To determine the quantal parameters before and after LT82 application, extracellular $\left[\mathrm{Ca}^{2+} / \mathrm{Mg}^{2+}\right]$ was modified between 2.1 and 0.14 as indicated in the bottom panel. Arrow denotes the time of LT injection. Solid lines denote the set of $I_{\text {mean }}$ determined by nonstationary analysis (with $w=9$ ). The horizontal, long-dashed line denotes average $I$ in the control period with $\left[\mathrm{Ca}^{2+} / \mathrm{Mg}^{2+}\right]=0.42$. Dashed line (after LT) denotes the extrapolated $I$ values (by sigmoid fitting) that would have been obtained without changing extracellular $\left[\mathrm{Ca}^{2+} / \mathrm{Mg}^{2+}\right] . B, C$, Top panels, Magnification of the $I=$ $f(t)$ plot portions boxed in A; bottom panels, the result of subtracting $I$ values from the $I_{\text {mean }}$ estimated using nonstationary analysis. $D, E$, The corresponding $\operatorname{Var}=f\left(I_{\text {mean }}\right)$ plots before $(\bigcirc)$ and after $(\bullet)$ LT action. The dashed straight line indicates that the initial release probability observed with $\left[\mathrm{Ca}^{2+} / \mathrm{Mg}^{2+}\right]=2.1$ was similar before and after LT. In $D$, the plots have been scaled to the $I_{\text {mean }}$ observed before changing $\left[\mathrm{Ca}^{2+} / \mathrm{Mg}^{2+}\right]$ and to the corresponding averaged Var. The identical initial slope of the parabolas indicates that quantal size, $q$, is not modified by LT.

$b^{*} I_{\text {mean }}^{2}$, and the corresponding $\operatorname{Var}=f\left(I_{\text {mean }}\right)$ plot would display a positive curvature pinpointing a change in $q$ size (Eq. 9). If $a>0$ and $b<0$, Var $=f\left(I_{\text {mean }}\right)$ plot would exhibit a negative curvature indicating a change in product $p_{o}{ }^{*} p_{A}$ (Eq. 3$)$.
A

B
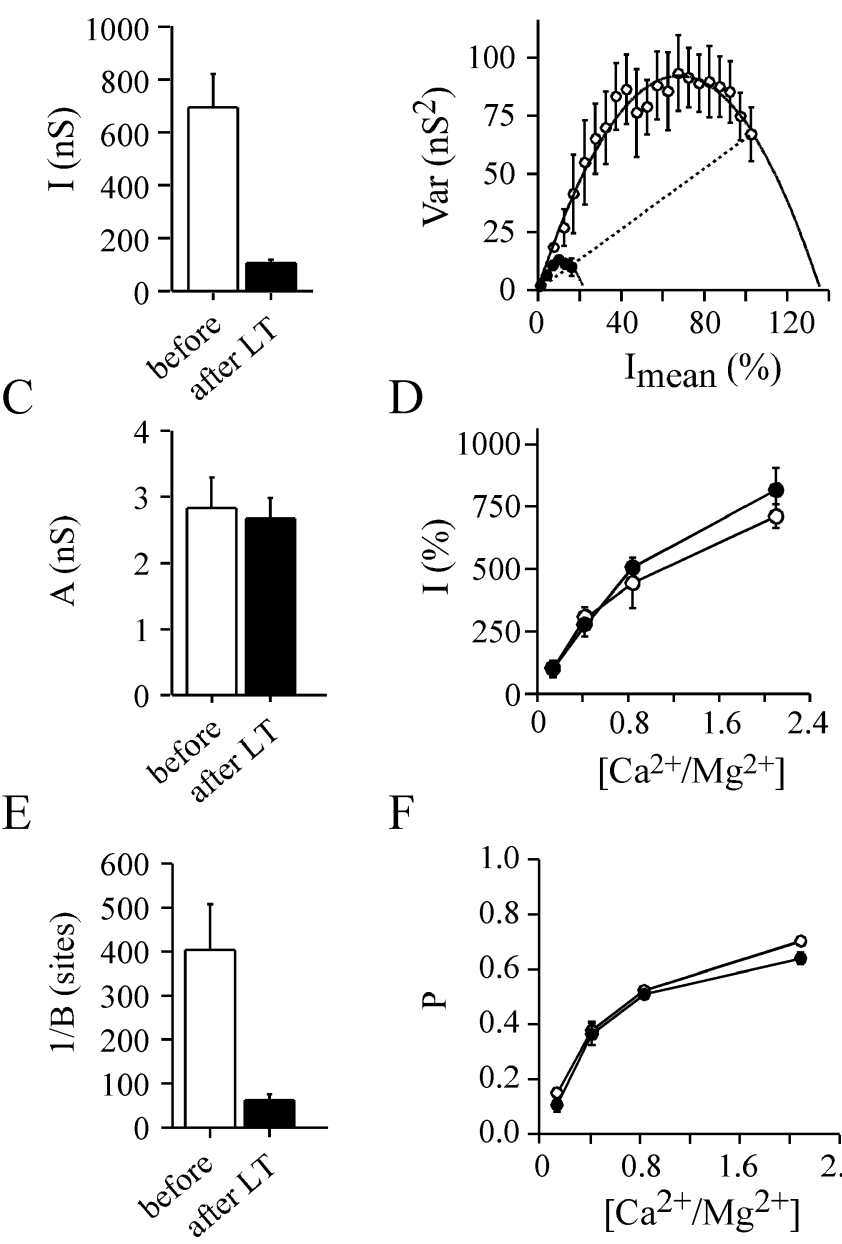

$\mathrm{D}$

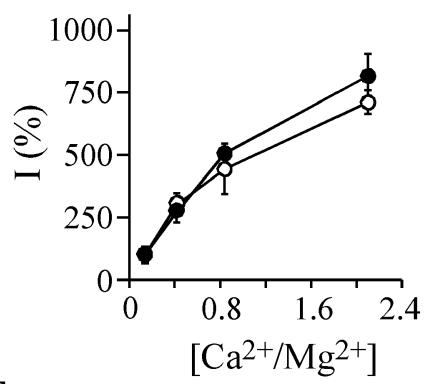

F

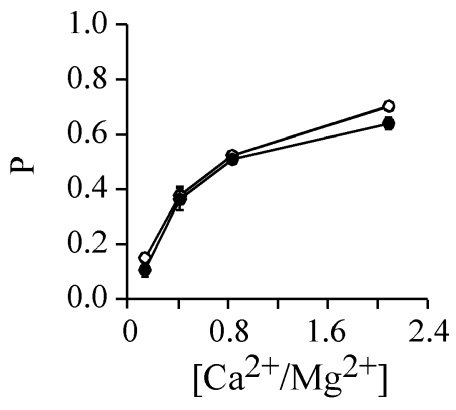

Figure 8. Determination of the parabola parameters affected by LT action using the fast change in extracellular $\left[\mathrm{Ca}^{2+} / \mathrm{Mg}^{2+}\right]$ protocol. Five experiments similar to that illustrated in Figure $6 B$ were analyzed before (open bars or open symbols) and $190 \pm 20$ min (mean \pm SD) after LT injection (closed symbols or filled bars). $A$, The mean IPSC amplitude. $B$, Mean $\operatorname{Var}=f\left(I_{\text {mean }}\right)$ plot was obtained by averaging the Var values for $I_{\text {mean }}$ over a 5\% amplitude interval. $C$, The average parameter $A$ of the adjusted parabolas, which refers to quantal size, $q$. $D$, The relationships between IPSC amplitude and extracellular $\left[\mathrm{Ca}^{2+} / \mathrm{Mg}^{2+}\right]$. The data were normalized to values observed at $\left[\mathrm{Ca}^{2+} / \mathrm{Mg}^{2+}\right]=0.14$ to highlight possible differences. $E$, The average $1 / B$ ratio, which refers to $n$. $F$, Relationships between $P$ parameter (see Eq. 8), which refers to $p_{\mathrm{o}}{ }^{*} p_{A}$, and extracellular $\left[\mathrm{Ca}^{2+} / \mathrm{Mg}^{2+}\right]$. In $A, B$, and $E$, a significant difference $(p<0.001)$ was found compared with controls; $C, D$, and $F$ show a nonsignificant difference $(p>0.5)$.

In Figure $11 A_{3}$, the parameters for nonlinear regression analysis of the $\operatorname{Var}=f\left(I_{\text {mean }}\right)$ plot were $a=0.68$ and $b=10^{-4}\left(r^{2}=\right.$ 0.88) (dashed line). The mean adjustment parameter for the 11 LT82 and 5 LT9048 experiments analyzed (Fig. $11 B, C$ ) were $a=$ $0.83, b=1.410^{-3}, r^{2}=0.78$, and $a=1.12, b=-0.810^{-3}, r^{2}=$ 0.76 , respectively. In all cases, $b$ approaches to 0 , indicating that $\operatorname{Var}=f\left(I_{\text {mean }}\right)$ is of the form Var $=a^{*} I_{\text {mean }}$. Accordingly, good adjustments of the $\operatorname{Var}=f\left(I_{\text {mean }}\right)$ plots were also obtained using linear regressions: Figure $11 A_{3}: a=0.73, r^{2}=0.83$; Figure $11 B$ : $a=0.97, r^{2}=0.77$; Figure 11C: $a=1.03, r^{2}=0.75$. Therefore, the relationships between Var and $I_{\text {mean }}$ when LT82 or LT9048 blocks ACh release are likely to be linear, and this graphically confirms that inactivation of Rac by LT causes inhibition of ACh release by reducing the number of release sites. 

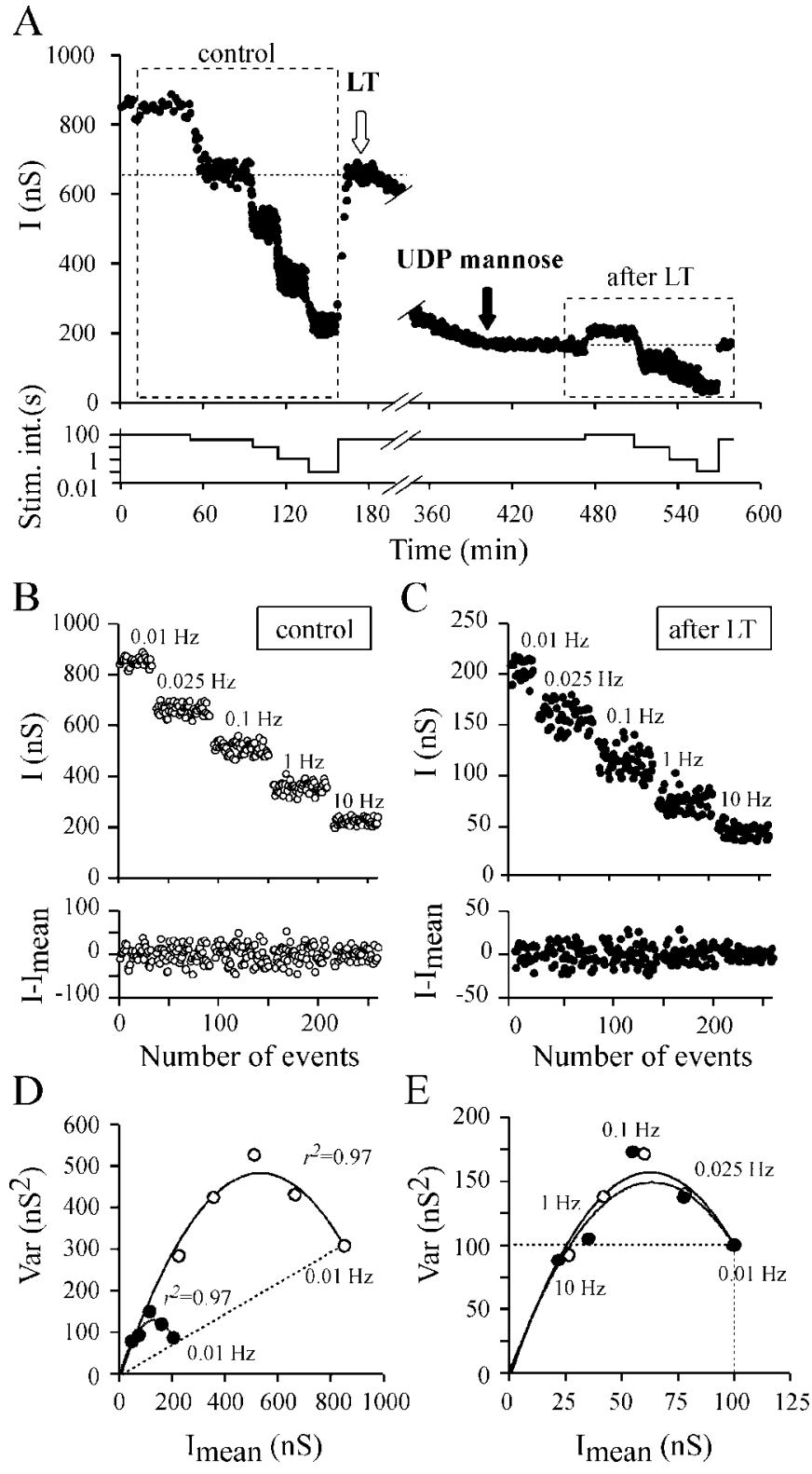

Figure 9. The effects of changing stimulation rate before and during LT action. A representative experiment of a series of four is illustrated. A, Top panel, To determine the quantal parameters before and after LT82 injection (white arrow), ACh release was modified by increasing the stimulation rate between 0.01 and $10 \mathrm{~Hz}$ to change release probability. The inhibitory action of LT was arrested by injection (black arrow) of UDP-mannose $(10 \mathrm{mM}$, final). Bottom panel indicates the different stimulation intervals used during the experiment. $B, C$, Top panels, The IPSC amplitudes are observed at the indicated stimulation rate and correspond to the data boxed in A. Bottom panels, The result of subtracting $I$ values from $I_{\text {mean }}$ (stationary analysis). $D$, The corresponding $\operatorname{Var}=f\left(I_{\text {mean }}\right)$ plots before $(O)$ and after $(\bullet)$ LT action. The dashed straight line indicates that release probability observed at a stimulation rate of $0.01 \mathrm{~Hz}$ is similar before and after LT. E, The plots reported in $D$ have been scaled to the $I_{\text {mean }}$ observed at $0.01 \mathrm{~Hz}$ and to the corresponding averaged Var. The identical initial slope of the parabolas indicates that quantal size is not modified by LT.

As an outcome of this study, one may anticipate that the graphical procedure described above [see also Humeau et al. (2001b)] may help to identify the quantal parameter(s) modified when synaptic efficacy is changed in response to a treatment.
A
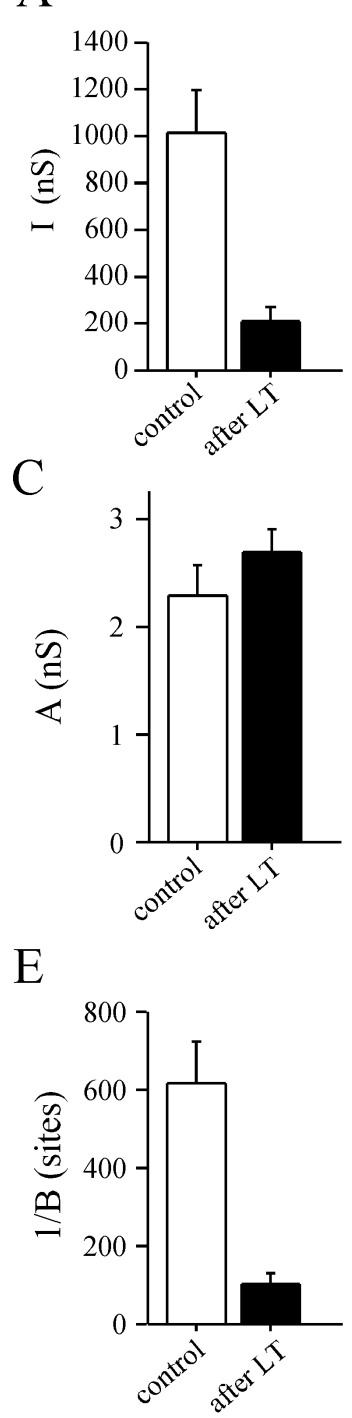

B

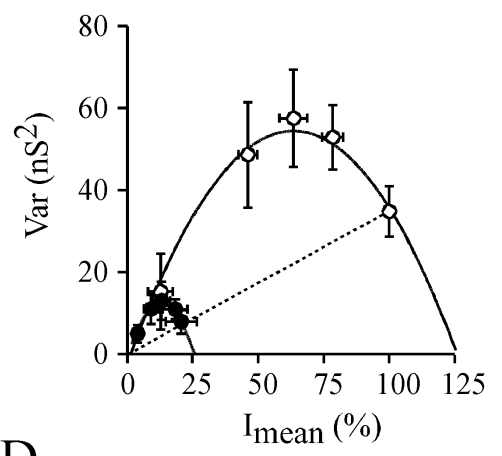

D

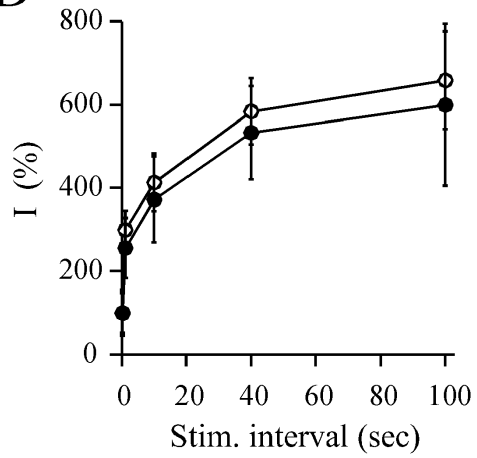

$\mathrm{F}$

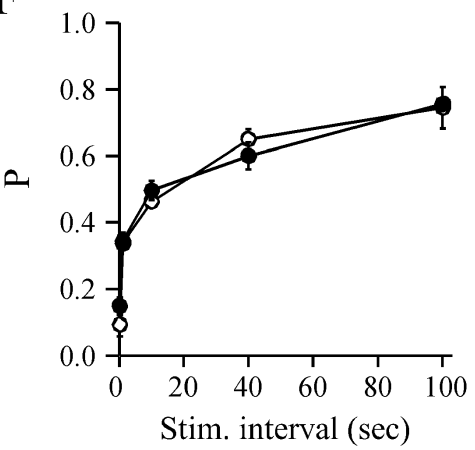

Figure 10. Determination of the parabola parameters before and after LT action using the change in stimulation rate protocol. Same presentation as in Figure 8, except that changes in the stimulation rate were used to modify release probability. In $B, I_{\text {mean }}$ and Var values were averaged for similar stimulation rate conditions. Averages were made from four successful experiments. In $A, B$, and $E$, a significant difference $(p<0.001)$ was found compared with controls; $C, D$, and $F$ show a nonsignificant difference $(p>0.5)$.

\section{DISCUSSION}

\section{Rac is the LT target by which glucosylation inhibits neurotransmitter release}

LT potently inhibits exocytosis in chromaffin cells (Gasman et al., 1999), RBL mast cells (Djouder et al., 2000), and neurons (Doussau et al., 2000; this study). Our results demonstrate that the blocking action of LT on neuroexocytosis is causally linked to glucosylation of small GTPases but not to other toxin activities. LT82 (which has effects on Rac, Ras, Ral, and Rap), LT9048 (which acts on Rac, Ras, Cdc42, and Rap), and Toxin B from Clostridium difficile (which glucosylates Rho, Rac, and Cdc42) share common characteristics: all three block ACh release (Doussau et al., 2000; this study), and this inhibitory action can be transiently relieved by stimulating neurons at a high frequency [Toxin B and LT82 (Doussau et al., 2000); LT9048 (data not 

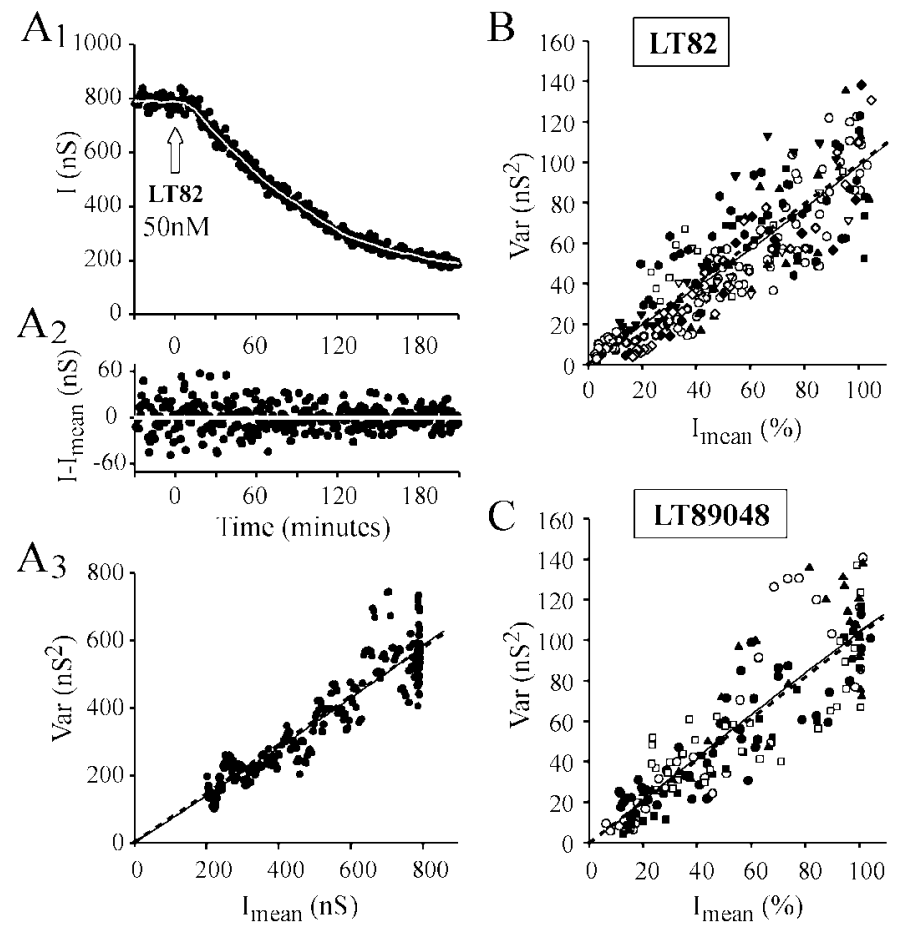

Figure 11. Graphical determination of $n$ as the quantal parameter modified by LT action. A, IPSC fluctuations during the course of LT82induced blockage of ACh release were analyzed by nonstationary analysis using a window width for local linear fitting $w=33$, and variance window $W=21 . A_{1}, I=f(t)$ plot. The set of $I_{\text {mean }}$ is represented by a solid white line. $A_{2}$, The result of subtracting $I$ values from $I_{\text {mean }} . A_{3}$, The corresponding $\operatorname{Var}=f\left(I_{\text {mean }}\right)$ plot. $B, C$, The Var $=f\left(I_{\text {mean }}\right)$ plots from experiments in which either LT82 $(n=11)$ or LT9048 $(n=5)$ was injected. Individual plots are indicated by different symbols and are scaled to the $I_{\text {mean }}$ and Var values determined before LT injection. For clarity, only 1 point of 10 is plotted. $A_{3}-C$, The adjustment of the data by linear (solid straight line) or nonlinear regression analysis (dashed curves) is presented. For $r^{2}$ values see Results. The linear Var $=f\left(I_{\text {mean }}\right)$ relationships indicate that $I_{\text {mean }}$ diminution is caused by a decrease in $n$, the number of active release sites.

shown)]. Because Rac is the only GTPase modified by these toxins, inactivation of Rac is likely to be responsible for the inhibition of ACh release.

Glucosylation of the other GTPases present in nerve tissue does not seem to contribute to the blocking action of LT. First, Ras and Rap are absent or minor components of nerve terminals, and Ras is preferentially localized at postsynaptic sites (Kim et al., 1990; Huber at al., 1994). Second, although Ral is abundant in nerve terminals and is associated with vesicles (Bielinski et al., 1993; Huber et al., 1994; Luo et al., 1998), LT9048, which has no activity against Ral (El Hadj et al., 1999; this paper), and LT82, which glucosylates Ral, exert similar block on ACh release. Moreover, TDP-glucose, which prevents glucosylation of Ras, Ral, and Rap but not Rac, does not antagonize LT inhibitory action, whereas UDP-mannose, which inhibits glucosylation of Ras, Ral, Rap, and Rac, completely prevents blockage of ACh exocytosis by LT. These data provide further support for the deduction that glucosylation of only Rac causes inhibition of exocytosis.

\section{Functional consequences of the glucosylation of Rac}

The effect of glucosylation on the GTPase cycle has been studied extensively (Herrmann et al., 1998; Sehr et al., 1998; Busch and Aktories, 2000; Just and Boquet, 2000; Vetter et al., 2000). To summarize, only GDP-bound GTPase is susceptible to glucosylation by LT. Glucosylated GTPase can bind to its target membrane and undergo GDP-GTP exchange stimulated by guanylate exchange factors. However, the GTP-bound form of glucosylated GTPase cannot stimulate protein effectors. The silencing of the downstream pathways is likely to be persistent because glucosylated GTPase does not cycle normally: its interaction with guanylate- activating protein is mostly reduced, and glucosylation affects a residue (Thr 35 in Rac and Ras) essential for GTP hydrolysis. The GTPase remains GTP bound but inactive and cannot be removed from target membranes by guanylate dissociation inhibitor. Therefore, GTP-bound glucosylated Rac should behave as a dominant negative mutant of Rac. This is fully consistent with our findings. Although UDP-mannose immediately arrests LT action, we observed no recovery of ACh release over the next $6 \mathrm{hr}$.

\section{How can Rac glucosylation cause reduction in the number of active release sites?}

To identify the release step(s) altered by LT action (i.e., the release step controlled by Rac), we determined the quantal release parameters modified after LT action. We found no change in either quantal size $(q)$ or average release probability $\left(p_{o}{ }^{*} p_{A}\right)$. Only the number of active release sites, $n$, appears to be strongly reduced. As discussed above, incorporation of glucosylated Rac in the release machinery is likely to cause a prolonged inactivation of the release site (i.e., that appears permanent or irreversible over the duration of the experiment). Therefore, does the reduction in $n$ mean that release sites have been physically eliminated (true reduction in $n$ ) or that they have been inactivated in a long-lasting manner? Indeed, setting in an all-or-none manner the product $p_{o}{ }^{*} p_{A}$ at a given release site to 0 should result in an apparent reduction in $n$. These possibilities are discussed below.

Mutations that affect interaction of Rho proteins (Rho, Rac, Cdc42) with effectors or GTP hydrolysis are known to induce remodeling of neuron morphology and diminution in neurite branching (Luo, 2000; Nakayama et al., 2000; Liu and Strittmatter, 2001). However, the reduction in number of active release sites is unlikely to result from retraction of synaptic buttons. Indeed, ACh release can recover initial levels in $<1 \mathrm{sec}$ by applying high-frequency stimulations (Doussau et al., 2000). This indicates that release sites are physically present but inactivated.

Rac is a well known regulator of the actin-based cytoskeleton (Hall, 1998; Bishop and Hall 2000), and inactivation of $\mathrm{Ca}^{2+}$ influx has been reported after actin-based cytoskeleton has been severed (Johnson and Byerly, 1993, 1994). Therefore, the possibility that inactivation of release site is caused by an altered $\mathrm{Ca}^{2+}$ influx should be considered. Consistent with our previous observation that paired-pulse facilitation is unaffected by LT (Doussau et al., 2000), we found that average $p_{o}{ }^{*} p_{A}$ remains unchanged after LT (Figs. 8, 9). This shows that the coupling between $\mathrm{Ca}^{2+}$ influx and exocytosis is intact at the sites that are still able to release after LT treatment. What about the inactivated release sites? At certain synapses, only one channel needs to open to trigger transmitter release (for review, see Stanley, 1997; Augustine, 2001). In this case, the permanent disabling of this channel after LT action should set local $p_{o}{ }^{*} p_{A}$ to 0 , leading to the apparent elimination of the release site (i.e., expressed as a reduction in $n$ ). However, at other synapses, several channels are required for transmitter release (Borst and Sakmann, 1996; Schneggenburger and Neher, 2000). This is likely to be the 
case at Aplysia synapses. Indeed, we observed that the slow $\mathrm{Ca}^{2+}$-buffer EGTA blocks transmitter release (Doussau et al., 1998). This suggests that (1) the open $\mathrm{Ca}^{2+}$ channels and fusion particle are distant and (2) several channels contribute to the calcium microdomain that triggers release. Therefore, the mechanism by which LT inhibits ACh release cannot be caused by the inactivation of a fraction of the $\mathrm{Ca}^{2+}$ channels. Indeed, a decrease in local $p_{o}{ }^{*} p_{A}$ should have been detected at the macroscopic level as a decrease in average $p_{o}{ }^{*} p_{A}$ but not as a change in $n$.

Because LT-poisoned nerve terminals can respond normally to changes in stimulation frequency, SV traffic and priming are normal (i.e., also the unchanged $p_{o}{ }^{*} p_{A}$ ) at the sites that remain active after LT treatment. Nevertheless, this does not preclude the possibility that an alteration in the supply of "ready to fuse" $\mathrm{SV}$ to release sites is the cause of the functional elimination of release sites. Indeed, if the supply of certain release sites is permanently blocked (i.e., local $p_{o}{ }^{*} p_{A} \rightarrow 0$ ), this should express as an apparent $n$ modification. Several possibilities should be considered. Actin filaments are present in the highly structured presynaptic density (Phillips et al., 2001). Consistent with the implication of Rac in actin cytoskeleton organization, it is conceivable that glucosylation of Rac may have disrupted the SV traffic along actin filaments. However, it is not known whether a release site is connected with a single actin filament. Recently, Rac and also Rho, Cdc42, Ral, and PLD1 have been shown to participate in a multiprotein complex that comprises Sec6/Sec 8 proteins, termed "exocyst" (Brymora et al., 2001; Guo et al., 2001; Moskalenko et al., 2002; Short and Barr, 2002), which is present in nerve terminals and growth cones (Hazuka et al., 1999; Brymora et al., 2001; Vega and Hsu, 2001). The exocyst is believed to regulate polarized secretion and docking of vesicles to regions of the plasma membrane specialized in exocytosis, possibly in a one-to-one stoichiometry with fusion sites (for review, see Short and Barr, 2002). Therefore, inactivation of Rac in the exocyst might be responsible for disrupting the supply of SV to release sites in an all-or-none manner. However, the data available on exocyst function suggest that it plays a major role in tethering vesicles to plasma membrane. This is not compatible with our previous observation that full recovery of ACh release can be obtained in $\sim 1 \mathrm{sec}$ by applying tetanic stimulation to LTpoisoned terminals (Doussau et al., 2000). One second is shorter than the mean residency time $(2-5 \mathrm{sec})$ for the SV docking stage before fusion at release sites (Klingauf et al., 1998; Murthy and Stevens, 1999). Thus, the SVs recruited for recovery are likely to be tethered or docked at an active zone. Therefore, glucosylated Rac is likely to act downstream of the step regulated by exocyst.

\section{Rac: a regulator of the fusion competence of plasma membrane?}

Two Rac-mediated pathways compatible with a post-docking role for Rac need to be considered. First, Rac stimulates phosphatidylinositol kinases (Hartwig et al., 1995; Bokoch et al., 1996), and phosphoinositides are key regulators for exo-endocytosis because they can specifically target proteins to fusion sites (Martin, 2001; Osborne et al., 2001). Second, PLD1 is inhibited at LTpoisoned cells (El Hadj et al., 1999), and Rac regulates PLD1 activity (Hammond et al., 1997). PLD1 is associated with release sites and has recently been implicated in exocytosis in both chromaffin cells (Vitale et al., 2001) and Aplysia neurons. In the latter case, PLD activity was shown to be crucial for determining the number of active release sites (Humeau et al., 2001b). Therefore, during tethering or docking of SVs, SV-associated Rac may stimulate hydrolysis of membrane phosphatidylcholine by PLD1. This generates phosphatidic acid, which favors formation of lipid bilayer intermediates during membrane fusion (Chernomordik et al., 1995; Monck and Fernandez, 1996). To conclude, the present analysis of LT action on presynaptic mechanisms reveals an essential role for Rac in the exocytotic mechanism, possibly by regulating lipid composition at the fusion site.

\section{REFERENCES}

Augustine GJ (2001) How does calcium trigger neurotransmitter release? Curr Opin Neurobiol 11:320-326.

Bielinski DF, Pyun HY, Linko-Stentz K, Macara IG, Fine RE (1993) Protein Ral and Rab3a are major GTP-binding proteins of axonal rapid transport and synaptic vesicles and do not redistribute following depolarization stimulated synaptosomal exocytosis. Biochim Biophys Acta 1151:246-256.

Bishop AL, Hall A (2000) Rho GTPases and their effector proteins. Biochem J 348:241-255.

Bokoch GM, Vlahos CJ, Wang Y, Knaus UG, Traynor-Kaplan AE (1996) Rac GTPase interacts specifically with phosphatidylinositol 3-kinase. Biochem J 315:775-779.

Borst JG, Sakmann B (1996) Calcium influx and transmitter release in a fast CNS synapse. Nature 383:431-434.

Brown AM, O'Sullivan AJ, Gomperts BD (1998) Induction of exocytosis from permeabilized mast cells by the guanosine triphosphatases Rac and Cdc42. Mol Biol Cell 9:1053-1063.

Brown TH, Perkel DH, Feldman MW (1976) Evoked neurotransmitter release: statistical effects of nonuniformity and nonstationarity. Proc Natl Acad Sci USA 73:2913-2917.

Brymora A, Valova VA, Larsen MR, Roufogalis BD, Robinson PJ (2001) The brain exocyst complex interacts with RalA in a GTPdependent manner: identification of a novel mammalian Sec3 gene and a second Sec15 gene. J Biol Chem 276:29792-29797.

Busch C, Aktories K (2000) Microbial toxins and the glucosylation of rho family GTPases. Curr Opin Struct Biol 10:528-535.

Busch C, Hofmann F, Selzer J, Munro S, Jeckel D, Aktories K (1998) A common motif of eukaryotic glycosyltransferases is essential for the enzyme activity of large clostridial cytotoxins. J Biol Chem 273:19566-19572.

Busch C, Hofmann F, Gerhard R, Aktories K (2000) Involvement of a conserved tryptophan residue in the UDP-glucose binding of large clostridial cytotoxin glycosyltransferases. J Biol Chem 275:13228-13234.

Chernomordik L, Chanturiya A, Green J, Zimmerberg J (1995) The hemifusion intermediate and its conversion to complete fusion: regulation by membrane composition. Biophys J 69:922-929.

Clements JD, Silver RA (2000) Unveiling synaptic plasticity: a new graphical and analytical approach. Trends Neurosci 23:105-113.

Dickson BJ (2001) Rho GTPases in growth cone guidance. Curr Opin Neurobiol 11:103-110.

Djouder N, Prepens U, Aktories K, Cavalie A (2000) Inhibition of calcium release-activated calcium current by $\mathrm{Rac} / \mathrm{Cdc} 42$-inactivating clostridial cytotoxins in RBL cells. J Biol Chem 275:18732-18738.

Doussau F, Clabecq A, Henry J-P, Darchen F, Poulain B (1998) Calcium-dependent regulation of Rab3 in short-term plasticity. J Neurosci 18:3147-3157.

Doussau F, Gasman S, Humeau Y, Vitiello F, Popoff M, Boquet P, Bader MF, Poulain B (2000) A Rho-related GTPase is involved in $\mathrm{Ca}^{2+}$. dependent neurotransmitter exocytosis. J Biol Chem 275:7764-7770.

El Hadj NB, Popoff MR, Marvaud JC, Payrastre B, Boquet P, Geny B (1999) G-protein-stimulated phospholipase D activity is inhibited by lethal toxin from Clostridium sordellii in HL-60 cells. J Biol Chem 274:14021-14031.

Gardner D (1971) Bilateral symmetry and interneuronal organization in the buccal ganglia of Aplysia. Science 173:550-553.

Gardner D, Stevens CF (1980) Rate-limiting step of inhibitory postsynaptic current decay in Aplysia buccal ganglia. J Physiol (Lond) 304:145-164.

Gasman S, Chasserot-Golaz S, Hubert P, Aunis D, Bader MF (1998) Identification of a potential effector pathway for the trimeric Go protein associated with secretory granules. Go stimulates a granule-bound phosphatidylinositol 4-kinase by activating RhoA in chromaffin cells. J Biol Chem 273:16913-16920.

Gasman S, Chasserot-Golaz S, Popoff MR, Aunis D, Bader MF (1999) Involvement of Rho GTPases in calcium-regulated exocytosis from adrenal chromaffin cells. J Cell Sci 112:4763-4771.

Green GA, Schue V, Monteil H (1995) Cloning and characterization of 
the cytotoxin L-encoding gene of Clostridium sordellii: homology with Clostridium difficile cytotoxin B. Gene 161:57-61.

Guo W, Tamanoi F, Novick P (2001) Spatial regulation of the exocyst complex by Rho1 GTPase. Nat Cell Biol 3:353-360.

Hall A (1998) Rho GTPases and the actin cytoskeleton. Science 279:509-514.

Hammond SM, Jenco JM, Nakashima S, Cadwallader K, Gu Q, Cook S, Nozawa Y, Prestwich GD, Frohman MA, Morris AJ (1997) Characterization of two alternately spliced forms of phospholipase D1. Activation of the purified enzymes by phosphatidylinositol 4, 5-bisphosphate, ADP-ribosylation factor, and Rho family monomeric GTP-binding proteins and protein kinase C-alpha. J Biol Chem 272:3860-3868.

Hartwig JH, Bokoch GM, Carpenter CL, Janmey PA, Taylor LA, Toker A, Stossel TP (1995) Thrombin receptor ligation and activated Rac uncap actin filament barbed ends through phosphoinositide synthesis in permeabilized human platelets. Cell 82:643-653.

Hazuka CD, Foletti DL, Hsu SC, Kee Y, Hopf FW, Scheller RH (1999) The sec6/8 complex is located at neurite outgrowth and axonal synapseassembly domains. J Neurosci 19:1324-1334.

Herrmann C, Ahmadian MR, Hofmann F, Just I (1998) Functional consequences of monoglucosylation of Ha-Ras at effector domain amino acid threonine 35. J Biol Chem 273:16134-16139.

Hofmann F, Busch C, Aktories K (1998) Chimeric clostridial cytotoxins: identification of the N-terminal region involved in protein substrate recognition. Infect Immunol 66:1076-1081.

Hong-Geller E, Cerione RA (2000) Cdc42 and Rac stimulate exocytosis of secretory granules by activating the IP(3)/calcium pathway in RBL2H3 mast cells. J Cell Biol 148:481-494.

Huber LA, Ullrich O, Takai Y, Lutcke A, Dupree P, Olkkonen V, Virta H, de Hoop MJ, Alexandrov K, Peter M, Zerial M, Simons K (1994) Mapping of Ras-related GTP-binding proteins by GTP overlay following two-dimensional gel electrophoresis. Proc Natl Acad Sci USA 91:7874-7878.

Humeau Y, Doussau F, Vitiello F, Greengard P, Benfenati F, Poulain B (2001a) Synapsin controls both reserve and releasable synaptic vesicle pools during neuronal activity and short-term plasticity in Aplysia. J Neurosci 21:4195-4206.

Humeau Y, Vitale N, Chasserot-Golaz S, Dupont JL, Du G, Frohman MA, Bader MF, Poulain B (2001b) A role for phospholipase D1 in neurotransmitter release. Proc Natl Acad Sci USA 98:15300-15305.

Johnson BD, Byerly L (1993) A cytoskeletal mechanism for Ca2+ channel metabolic dependence and inactivation by intracellular $\mathrm{Ca} 2+$. Neuron 10:797-804.

Johnson BD, Byerly L (1994) Ca2+ channel Ca(2+)-dependent inactivation in a mammalian central neuron involves the cytoskeleton. Pflügers Arch 429:14-21.

Just I, Boquet P (2000) Large clostridial cytotoxins as tools in cell biology. Curr Top Microbiol Immunol 250:97-107.

Just I, Selzer J, Hofmann F, Green GA, Aktories K (1996) Inactivation of Ras by Clostridium sordellii lethal toxin-catalyzed glucosylation. J Biol Chem 271:10149-10153.

Kehoe J, McIntosh JM (1998) Two distinct nicotinic receptors, one pharmacologically similar to the vertebrate $\alpha 7$-containing receptor, mediate Cl currents in Aplysia neurons. J Neurosci 18:8198-8213.

Kim S, Mizoguchi A, Kikuchi A, Takai Y (1990) Tissue and subcellular distributions of the smg-21/rap1/Krev-1 proteins which are partly distinct from those of c-ras p21s. Mol Cell Biol 10:2645-2652.

Klingauf J, Kavalali ET, Tsien RW (1998) Kinetics and regulation of fast endocytosis at hippocampal synapses. Nature 394:581-585.

Kowluru A, Li G, Rabaglia ME, Segu VB, Hofmann F, Aktories K, Metz SA (1997) Evidence for differential roles of the Rho subfamily of GTP-binding proteins in glucose- and calcium-induced insulin secretion from pancreatic beta cells. Biochem Pharmacol 54:1097-1108.

Linseman DA, Laessig T, Meintzer MK, McClure M, Barth H, Aktories K, Heidenreich KA (2001) An essential role for Rac/Cdc42 GTPases in cerebellar granule neuron survival. J Biol Chem 276:39123-39131.

Liu BP, Strittmatter SM (2001) Semaphorin-mediated axonal guidance via Rho-related G proteins. Curr Opin Cell Biol 13:619-626.

Luo JQ, Liu X, Frankel P, Rotunda T, Ramos M, Flom J, Jiang H, Feig LA, Morris AJ, Kahn RA, Foster DA (1998) Functional association between Arf and RalA in active phospholipase D complex. Proc Natl Acad Sci USA 95:3632-3637.

Luo L (2000) Rho GTPases in neuronal morphogenesis. Nat Rev Neurosci 1:173-180.

Martin TF (2001) $\mathrm{PI}(4,5) \mathrm{P}(2)$ regulation of surface membrane traffic. Curr Opin Cell Biol 13:493-499.

Meyer AC, Neher E, Schneggenburger R (2001) Estimation of quantal size and number of functional active zones at the calyx of Held synapse by nonstationary EPSC variance analysis. J Neurosci 21:7889-7900.

Meyer DK, Olenik C, Hofmann F, Barth H, Leemhuis J, Brunig I, Aktories K, Norenberg W (2000) Regulation of somatodendritic $\mathrm{GABA}_{\mathrm{A}}$ receptor channels in rat hippocampal neurons: evidence for a role of the small GTPase Rac1. J Neurosci 20:6743-6751.
Monck JR, Fernandez JM (1996) The fusion pore and mechanisms of biological membrane fusion. Curr Opin Cell Biol 8:524-533.

Moskalenko S, Henry DO, Rosse C, Mirey G, Camonis JH, White MA (2002) The exocyst is a Ral effector complex. Nat Cell Biol 4:66-72.

Mota M, Reeder M, Chernoff J, Bazenet CE (2001) Evidence for a role of mixed lineage kinases in neuronal apoptosis. J Neurosci 21:4949-4957.

Murthy VN, Stevens CF (1999) Reversal of synaptic vesicle docking at central synapses. Nat Neurosci 2:503-507.

Murthy VN, Sejnowski TJ, Stevens CF (1997) Heterogeneous release properties of visualized individual hippocampal synapses. Neuron 18:599-612.

Nakayama AY, Harms MB, Luo L (2000) Small GTPases Rac and Rho in the maintenance of dendritic spines and branches in hippocampal pyramidal neurons. J Neurosci 20:5329-5338.

Oleskevich S, Clements J, Walmsley B (2000) Release probability modulates short-term plasticity at a rat giant terminal. J Physiol (Lond) 524:513-523.

Osborne SL, Meunier FA, Schiavo G (2001) Phosphoinositides as key regulators of synaptic function. Neuron 32:9-12.

Phillips GR, Huang JK, Wang Y, Tanaka H, Shapiro L, Zhang W, Shan WS, Arndt K, Frank M, Gordon RE, Gawinowicz MA, Zhao Y, Colman DR (2001) The presynaptic particle web: ultrastructure, composition, dissolution, and reconstitution. Neuron 32:63-77.

Popoff MR (1987) Purification and characterization of Clostridium sordellii lethal toxin and cross-reactivity with Clostridium difficile cytotoxin. Infect Immunol 55:35-43.

Popoff MR, Chaves-Olarte E, Lemichez E, von Eichel-Streiber C, Thelestam M, Chardin P, Cussac D, Antonny B, Chavrier P, Flatau G, Giry M, de Gunzburg J, Boquet P (1996) Ras, Rap, and Rac small GTPbinding proteins are targets for Clostridium sordellii lethal toxin glucosylation. J Biol Chem 271:10217-10224.

Poulain B, Baux G, Tauc L (1986) Presynaptic transmitter content controls the number of quanta released at a neuro-neuronal cholinergic synapse. Proc Natl Acad Sci USA 83:170-173.

Poulain B, Tauc L, Maisey EA, Wadsworth JD, Mohan PM, Dolly JO (1988) Neurotransmitter release is blocked intracellularly by botulinum neurotoxin, and this requires uptake of both toxin polypeptides by a process mediated by the larger chain. Proc Natl Acad Sci USA 85:4090-4094.

Prepens U, Just I, von Eichel-Streiber C, Aktories K (1996) Inhibition of Fc epsilon-RI-mediated activation of rat basophilic leukemia cells by Clostridium difficile toxin B (monoglucosyltransferase). J Biol Chem 271:7324-7329.

Quastel DM (1997) The binomial model in fluctuation analysis of quantal neurotransmitter release. Biophys J 72:728-753.

Redmond L, Ghosh A (2001) The role of Notch and Rho GTPase signaling in the control of dendritic development. Curr Opin Neurobiol 11:111-117.

Reid CA, Clements JD (1999) Postsynaptic expression of long-term potentiation in the rat dentate gyrus demonstrated by variance-mean analysis. J Physiol (Lond) 518:121-130.

Ridley AJ (2001) Rho family proteins: coordinating cell responses. Trends Cell Biol 11:471-477.

Robinson HP, Sahara Y, Kawai N (1991) Nonstationary fluctuation analysis and direct resolution of single channel currents at postsynaptic sites. Biophys J 59:295-304.

Rosenmund C, Clements JD, Westbrook GL (1993) Nonuniform probability of glutamate release at a hippocampal synapse. Science 262:754-757.

Scheuss V, Neher E (2001) Estimating synaptic parameters from mean, variance, and covariance in trains of synaptic responses. Biophys $\mathbf{J}$ 81:1970-1989.

Scheuss V, Schneggenburger R, Neher E (2002) Separation of presynaptic and postsynaptic contributions to depression by covariance analysis of successive EPSCs at the calyx of Held synapse. J Neurosci 22:728-739.

Schiavo G, Benfenati F, Poulain B, Rossetto O, Polverino de Laureto P, DasGupta BR, Montecucco C (1992) Protein tetanus and botulinum-B neurotoxins block neurotransmitter release by proteolytic cleavage of synaptobrevin. Nature 359:832-835.

Schneggenburger R, Neher E (2000) Intracellular calcium dependence of transmitter release rates at a fast central synapse. Nature 406:889-893.

Sehr P, Joseph G, Genth H, Just I, Pick E, Aktories K (1998) Glucosylation and ADP ribosylation of rho proteins: effects on nucleotide binding, GTPase activity, and effector coupling. Biochemistry 37:5296-5304.

Short B, Barr FA (2002) Membrane traffic: exocyst III-makes a family. Curr Biol 12:R18-20.

Sigworth FJ (1980) The variance of sodium current fluctuations at the node of Ranvier. J Physiol (Lond) 307:97-129. 
Silver RA, Momiyama A, Cull-Candy SG (1998) Locus of frequencydependent depression identified with multiple-probability fluctuation analysis at rat climbing fibre-Purkinje cell synapses. J Physiol (Lond) 510:881-902

Simonneau M, Tauc L, Baux G (1980) Quantal release of acetylcholine examined by current fluctuation analysis at an identified neuroneuronal synapse of Aplysia. Proc Natl Acad Sci USA 77:1661-1665.

Stanley EF (1997) The calcium channel and the organization of the presynaptic transmitter release face. Trends Neurosci 20:404-409.

Traynelis SF, Silver RA, Cull-Candy SG (1993) Estimated conductance of glutamate receptor channels activated during EPSCs at the cerebellar mossy fiber-granule cell synapse. Neuron 11:279-289.
Vega IE, Hsu SC (2001) The exocyst complex associates with microtubules to mediate vesicle targeting and neurite outgrowth. J Neurosci 21:3839-3848.

Vetter IR, Hofmann F, Wohlgemuth S, Herrmann C, Just I (2000) Structural consequences of mono-glucosylation of Ha-Ras by Clostridium sordellii lethal toxin. J Mol Biol 301:1091-1095.

Vitale N, Caumont AS, Chasserot-Golaz S, Du G, Wu S, Sciorra VA, Morris AJ, Frohman MA, Bader MF (2001) Phospholipase D1: a key factor for the exocytotic machinery in neuroendocrine cells. EMBO J 20:2424-2434.

Zucker RS (1989) Short-term synaptic plasticity. Annu Rev Neurosci 12:13-31. 